\title{
BUCHBESPRECHUNGEN
}

\author{
Claus Dieter Classen / Armin Dittmann / Frank Fechner / Ulrich M. Gassner / \\ Michael Kilian (Hrsg.) \\ „In einem vereinten Europa dem Frieden der Welt zu dienen...“ \\ Liber amicorum Thomas Oppermann \\ Tübinger Schriften zum Staats- und Verwaltungsrecht, Band 59 \\ Duncker \& Humblot Verlag, Berlin, 2001, 908 S., DM 196,--
}

Der Jubilar, einst Assistent bei Herbert Krüger, entfaltete, wie die Herausgeber im Vorwort vermerken (S. 5), ein wissenschaftliches Werk, das durch seine Breite beeindruckt und dessen wichtigste Schwerpunkte das Kulturverfassungs- und -verwaltungsrecht, das Europarecht und das internationale Wirtschaftsrecht bilden; ,,in diesen Bereichen liegt denn auch der thematische Schwerpunkt der Festschrift“. Insgesamt 45 Beiträge, davon sechs auf englisch, befassen sich mit Fragen von ,nationaler Integration und staatlicher Verfassunggebung“ (I.), legen Strecken ,auf dem Weg zu einer europäischen Verfassung“ (II.) zurück - hierunter finden sich eindrucksvolle Erinnerungen M. Kilians an Walter Hallstein (S. 119 ff.) -, setzen „Europa und die Welt“ (repräsentiert durch Israel, Polen, Tschechien und Japan!) in Beziehung (III.), ranken sich um die „Konstitutionalisierung der Weltwirtschaft“ (IV.), um nach eher - wenngleich nicht qualitativ - lückenbüßerischen Ausführungen zu „nationalem und internationalem Recht“(V.) noch einmal allgemein auf Probleme des ,internationalen, europäischen und deutschen Wirtschaftsrechts" (VI.) zurückzukommen, wobei die Überlegungen $F$. Kirchhofs besser in Teil V. gepaßt hätten. Aus den beiden letzten Teilen - „Kultur und Medien“ (VII.) sowie „Bildung und Wissenschaft“ (VIII.) mag für VRÜ-Leser vor allem der (auch vom Umfang her bedeutsame) Beitrag von Prott von Interesse sein, der die Frage aufwirft, ob ein ,international legal instrument for the protection of the intangible cultural heritage" angezeigt sei (S. $657 \mathrm{ff}$.).

Außer der auf das Oeuvre Oppermanns bezogenen inhaltlichen Strukturierung haben die Herausgeber den Autoren aus dem In- und Ausland recht freie Hand gelassen, auch was die Breite der Kontributionen ausmacht. Dies gerät schwerlich zum Nachteil, sondern erlaubt des öfteren über einen Essay weit hinausreichende Studien. Um nun einige zu nennen: $W$. Graf Vitzthum knüpft an das Interesse des Geehrten ,für ethno-politische Konflikte und ihre völker-, europa- und verfassungsrechtliche Hegung“ (S. 89) an und beleuchtet eine multiethnische Demokratie am Beispiel Bosnien-Herzegowinas. Verfassungsfragen der Europäischen Union erörtern aus durchaus unterschiedlicher Perspektive K. Stern, U. Everling - früher Weggefährte Oppermanns im Bundeswirtschaftsministerium -, G. Nicolaysen und P. Kirchhof, während sich G. Papastamkos speziell der EG-Wirtschafts-,,verfas- 
sung" zuwendet, Regulierungsleistungen und Politikverflechtungen aufzeigend (S. 219 ff.). Am Beispiel der Tschechischen Republik belegt G. Sander detailreich die Teilhabe mittelund osteuropäischer Staaten an wirtschaftlichen Integrationsräumen nicht nur im regionalen Rahmen, sondern auch im Kontext der WTO. Der von Oppermann literarisch häufig behandelten Welthandelsorganisation sind mehrere Beiträge ausgewiesener Sachkenner gewidmet: John J. Jackson skizziert ihre „evolving constitution“ und erweitert dabei den Blick auf (andere), ,international economic institutions“ (S. 411), M. Hilf erörtert - gleichsam im Vorgriff auf sein Referat auf der Frankfurter Völkerrechtslehrertagung im März 2001 - die seit Seattle 1999 ins Rampenlicht gerückte Frage der demokratischen Legitimation (S. 427 ff.); E.-U. Petersmann, langjähriger Mitstreiter im Rahmen der I.L.A., und $M$. Nettesheim, Oppermanns Nachfolger in Tübingen, entwerfen schließlich spezifische Konstitutionalisierungsszenarien (S. 367 ff., 381 ff.). In engem Bezug hierzu stehen Ausführungen J. Molsbergers zu ,Welthandelsordnung, Globalisierung und wirtschaftspolitische(r) Autonomie“ (S. 433 ff.). Dem stets auf praktische Durchführbarkeit ausgerichteten Ansatz des Jubilars tragen die Analysen K.-H. Böckstiegels und S. Wiessners zur (schiedsgerichtlichen) internationalen Streitbeilegung Rechnung (S. 439 ff., 453 ff.). Für den Autor eines Standard-Lehrbuchs zum Europarecht (2.A. 1999) überaus passend (und inhaltlich nachhaltig) sind Studien U.M. Gassners zu „Richtlinien mit Doppelwirkung“ (S. 503 ff.) und von P. Conlan zur Personenverkehrsfreiheit (S. 551 ff.), durch das nicht allein auf Welthandelsfragen bezogene Interesse Oppermanns veranlaßt zwei Beiträge zur Europäischen Währungsunion (H.J. Hahn, J. Starbatty, S. 609 ff., 627 ff.).

Der für ein Werk solcher Dicke (wie Breite und Tiefe) noch moderate Preis sollte auch in für öffentliche Bibliotheken prekären Zeiten den Erwerb der Festschrift erleichtern. Schade nur, daß es nach wie vor nicht üblich zu sein scheint, derartigen Büchern ein Sachregister beizugeben. Die Freundesgabe für Thomas Oppermann hätte diese Handreichung wahrlich verdient.

Ludwig Gramlich, Chemnitz

\section{H. Patrick Glenn}

\section{Legal Traditions of the World}

Sustainable Diversity in Law

Oxford University Press, Oxford / New York, 2000, 371 pp., £ 19.99 (Paperback)

Vor einigen Jahren machte der Harvard-Politologe Samuel Huntington Furore, als er, zunächst, 1993, in Form eines Artikels in Foreign Affairs (und mit Fragezeichen im Titel) und dann in Buch-Form (ohne Fragezeichen) den „Clash of Civilizations“ als wahrscheinliche Konfliktformation der internationalen Politik des 21. Jahrhunderts diagnostizieren zu 
müssen glaubte (das Buch erschien 1996 in New York, die deutsche Übersetzung noch im selben Jahr in München/Wien unter dem Titel „Kampf der Kulturen“). Die Reaktion auf diese These hierzulande, soweit sie kritisch war, war oft überwiegend normativ motiviert. Darob sollte nicht vergessen werden, dass die sich empirisch gebende These (wenngleich sie klar normative oder handlungsanleitende Implikationen hat) auch analytisch auf durchaus tönernen Füßen steht. Um nur die wichtigsten Einwände insofern zu wiederholen: Huntington überzeichnet die innere Einheitlichkeit der von ihm skizzierten Kulturen; er hypostasiert sie, das ist sozialwissenschaftlich besonders unplausibel, zu kollektiven Akteuren, und ein Gutteil der Suggestionskraft seiner Thesen lebt davon, dass das Bild etwa eines bedrohlichen Islam evoziert wird, der, wie ein Mann` gegen den Westen vorgeht; und, eine Einsicht des sozialwissenschaftlichen Konstruktivismus anwendend, könnte man vermuten, dass die Propagierung der Huntingtonschen Sichtweise jene Gefahr, die sie vermeintlich nur konstatiert, mit-herbeiredet, im Sinne einer sich selbst erfüllenden Prophezeiung: weil solche Publikationen eben auch in der nicht-westlichen Welt gelesen werden und von Hardlinern dort durchaus als Kampfansage verstanden werden und weil sich westliche Fundamentalisten in eben diesem Sinne zu Abwehrhandlungen motiviert sehen könnten.

Das hier vorzustellende Buch ist weit mehr als nur eine weitere Schrift wider Huntington (der gar nicht erwähnt wird). Und doch ist sie in vieler Hinsicht auch ein wirksames Antidot dazu. Dabei werden drei Ressourcen mobilisiert: das ungeheure Wissen über die großen Rechtstraditionen der Welt, das Glenn, Professor für Rechtswissenschaft an der McGill University in Montreal, sich angeeignet hat; eine im ganzen Buch zum Ausdruck kommende Philosophie der Erweiterung des eigenen geistigen Horizonts durch ernsthaftes Bemühen um Fremd-Verstehen; und die große Fähigkeit des Autors, beides in klarer, ansprechender Sprache zum Ausdruck zu bringen.

Letzteres zeigt sich bereits in der so gekonnten Formulierung des Untertitels. Er bringt sowohl die geistige Stoßrichtung der Arbeit zum Ausdruck als auch den Gegenstand, anhand dessen die im obigen Sinne philosophische Übung unternommen wird: die vergleichende Betrachtung des Rechts. Damit ist aber die Arbeit nicht nur für Freunde des Rechts(vergleiches) von Belang. Vielmehr ist sie, der Verlag weist zu Recht darauf hin, auch für alle sozial- und kulturwissenschaftlich an interkulturellem Dialog Interessierte von Interesse. Für beide Lesergruppen liegt der erste Gewinn des Buches in der kundigen Darlegung der Grundzüge von sieben großen Rechtstraditionen: der von Glenn so genannten chtonischen (von gr. kthonos = Erde), also der allenthalben am Anfang der Menschheitsund Rechtsentwicklung liegenden Tradition der noch natur-nah lebenden, ursprünglichen Gesellschaftsformen; der talmudischen Rechtstradition; der zivilrechtlichen Tradition (Rom und die Folgen); der islamischen Rechtstradition; der common law-Tradition; der des Hindu-Rechts und schließlich der asiatischen (konfuzianisch-buddhistischen) Rechtstradition. Wohl wenige, auch sehr an solch umfassend-rechtsvergleichender Betrachtung Interessierte werden in der Lage sein, allen hierzu von Glenn in fünf europäischen Sprachen angeführten Literaturhinweisen nachzugehen und damit seinen wohl jahrelangen Erkenntnisweg nachzuschreiten. Umso wichtiger ist es, dass er durch seine klare Darstellung (und 
die jederzeit Vertiefung ermöglichenden Literaturhinweise) den Lesern einer schnelllebigeren Zeit einen so profunden Ein- und Überblick ermöglicht. Geschildert werden jeweils die Hauptquellen der Rechtstraditionen, ihre wichtigsten Rechtsinstitute und im Überblick zentrale Elemente ihrer substanziellen Rechtsvorstellungen. Darüber hinaus jedoch wird jeweils auch die Einstellung der Traditionen zum Begriff des Wandels (change) und zu den Beziehungen zu anderen Traditionen dargestellt. Hierdurch verfolgt Glenn gleichsam indirekt sein philosophisches Anliegen, die Leser zunehmend zum interkulturellen Dialog zu befähigen.

Die Grundlage dafür liefert er in zwei einleitenden Kapiteln, die sich eher allgemein sozialtheoretisch mit dem Konzept der Tradition und den Beziehungen zwischen Traditionen beschäftigen. Der Rezensent, praktizierender Sozialwissenschaftler, war hier, dies sei eingeräumt, selbst zunächst eher skeptisch, was auf dieser Abstraktionsebene sinnvoll gesagt werden könne. Und Glenn selbst sagt im Vorwort, dass rein juristisch Interessierte diese Kapitel übergehen könnten. Nach ihrer Lektüre kann ich davon nur abraten: der Leser würde sich einiger hoch-interessanter, weit über den konkreten Zusammenhang des Buches hinaus belangvoller Gedanken zum Thema Tradition berauben, die etwa auch vorzüglich in ein anspruchsvolles Seminar zum Thema Konservatismus einfließen könnten (worüber der Rezensent seit geraumer Zeit nachdenkt ...). Der hier ausgeworfene Faden, den Glenn im Vorwort selbst auf die treffende Formel bringt: „Learning about tradition is taken to be a process of learning from traditions“ (xxii), zieht sich durch das ganze Buch. Im Kapitel über die asiatische Tradition werden abschließend die ,gefährlichen“ Folgen dieses Vorgehens offen benannt: „you will be easternized neither by force nor by insidious and persistent efforts of acculturation. You can be easternized, however, if you think about it (die asiatische Tradition, ML).“(S. 314)

Westlichen Fundamentalisten wird dies alles zu weit gehen. Sie werden ihre Felle davon schwimmen sehen - obwohl Glenn im Schlusskapitel zu Recht darauf hinweist, dass gerade interkulturelle Dialogfähigkeit Sicherheit erbringt: „It means seeing dominance, and efforts to obtain dominance, as a form of corruption of all major legal traditions (...). It also means seeing your own, particular tradition ... as secure“; und, direkt an die Vertreter der westlichen Traditionen gewandt: „So western, bivalent thinking does not somehow have to be abandoned, within western legal traditions. There need simply be recognition that multivalent thinking also exists, in other legal traditions“" (S. 333). Diese Anerkennung der jeweils anderen Traditionen (nicht nur ihre Toleranz, eine, so Glenn, „western idea“ die „ultimately a very unstable one“ sei [S. 328]) wird die im Untertitel angesprochene sustainable diversity in law ermöglichen. Voraussetzung dafür ist, dass jeder sich um ein aufrichtiges Verstehen des anderen bemüht, dabei auch versteht, dass alle großen Traditionen, auch die eigene, in sich vielfältig und komplex sind, und vor diesem Hintergrund dann auch Kritik von außen konstruktiv aufnehmen kann. Denn diese, das sei Fundamentalisten versichert, bleibt möglich - wenn sie glaubhaft auch am jeweils eigenen Standpunkt geübt wird. Freilich wird diese Philosophie Glenns eingefleischte Fundamentalisten aller Traditionen nicht wirklich überzeugen. Er leistet aber, am Beispiel der vergleichenden Betrach- 
tung des Rechts, das Bestmögliche dazu, dass deren Zahl - und damit unsere gemeinsamen Probleme - sich nicht noch weiter vermehren. Für westliche Leser öffnet er den Horizont zu zunächst fremden, anderen Traditionen, und je mehr ihm dies gelingt, desto eher wird auch der fremde Blick auf das Eigene möglich, das an Selbstverständlichkeit verliert (derselbe Effekt, den ein wacher längerer Aufenthalt im Ausland haben kann). Und nichtwestliche Leser werden hoffentlich zu schätzen wissen, wie weit ein führender Vertreter der westlichen akademischen Welt im aufrichtigen Bemühen um Fremdverstehen gelangen kann. Hier wäre geradezu zu wünschen, dass dies im oben erwähnten Sinne als sich selbst erfüllende Prophezeiung wirkt - nur eben genau in die andere Richtung als im Falle Huntington.

Es war wohl diese Kombination von vorzüglicher Sachdarstellung und unterstützenswerter philosophischer Perspektive, die die International Academy of Comparative Law veranlasst hat, Glenns Buch ihren großen Preis zuzuerkennen - völlig verdient. Verdienen würde das Buch auch zahlreiche westliche und nicht-westliche Leser. Der Rezensent wäre froh, hierzu einen Beitrag geleistet zu haben.

Martin List, Hagen

\section{Valeria Piergigli / Irma Taddia (Hrsg.)}

\section{International Conference on African Constitutions}

Centro italiano per lo sviluppo della ricerca, Collana diretta dal prof. Guiseppe de Vergottini

Verlag Giappichelli, Torino, 2000, 354 S., LIT 50.000

Der vorliegende Band umfasst die zahlreichen Referate in englischer und französischer Sprache, die im November 1998 auf einer Konferenz in Bologna zum afrikanischen Verfassungsrecht gehalten wurden. Geographisch beschränkt sich der Band auf das Afrika südlich der Sahara, thematisch geht es um die wichtigsten Verfassungsfragen in den einzelnen Ländern, sowohl des anglophonen, als auch des frankophonen wie des lusophonen Sprachraums. Bemerkenswerterweise beschäftigt sich Italien in wachsendem Masse mit dem afrikanischen Recht; Deutschland war auf der Tagung mit keinem Referenten und ist auch hier mit keinem Beitrag vertreten. Herausgegeben ist der Band von Professorinnen des Öffentlichen Rechts wie auch solchen der afrikanischen Geschichte. Das Werk zeichnet sich vor allem dadurch aus, dass es multidisziplinär angelegt ist: Neben der Verfassungsjurisprudenz kommen auch die Politik- und die Geschichtswissenschaft ebenso wie die Anthropologie zu Wort. Nachstehend soll nur ein kurzer Überblick über die wichtigsten Referate gegeben werden, wobei sich die Aufzählung auf Themen mit gesamtafrikanischem Bezug beschränkt: Francois Venter, The Emergence of Constitutionalism in Southern 
Africa in the late 20th Century; Babacar Kanté, L'évolution constitutionnelle des Etats d'Afrique francophone: Tendances récentes; Rodolfo Sacco-Luca Castellani, Le Constitutionnalisme Africain; Guglielmo Verdirame, Human Rights and African Constitutions: Some Observations; Valeria Piergigli, The reception of liberal constitutionalism and "Universal" values in the African Bill of Rights. Ambiguities and perspectives at the turn of the millennium; Uodelul Chelati Dirar, The issue of nationalities in Eritrean and Ethiopian constitutions: A historical perspective; Tekeste Negash, The landscape of African Constitutions: Some concluding remarks.

Den Referaten ist eine Einführung vorangestellt, welche allgemeine Zielrichtung wie Telos der Konferenz und der Publikation umschreibt. Wichtige Aspekte und Grundlagen für die Untersuchungen sind zwei historische Fakten: Der Zusammenbruch der Sowjetunion wie auch ihres Einflusses auf Afrika einerseits und der Zusammenbruch afrikanischer Militärdiktaturen, gefolgt von einem breiten Demokratisierungsprozess andererseits. Beide Faktoren spielten etwa in Äthiopien eine maßgebliche Rolle - auch hier gab es 1991 eine „Transitional Period Charta“, nachdem die Militärdiktatur Mengistus und der Einfluss der Sowjetunion weggefallen waren. Die Konferenz widmete eigentümlicherweise der Entwicklung in Eritrea und Äthiopien sehr wenig Beachtung, obwohl Italien über ein Jahrhundert diesbezüglich auch eine wissenschaftliche Führungsrolle gespielt hat. Werden solche „Constituent Constitutions“ zeitlich zu weit erstreckt, fehlt es dann doch entweder an der Rechtssicherheit der Verfassung, oder man darf nicht von Vorläufigkeit und Übergang sprechen. Inwieweit die neuen Regime aufgrund der demokratischen Prozesse wirklich zu einem Pluralismus geführt haben, mag angesichts der Verhältnisse in Simbabwe oder Äthiopien bezweifelt werden. Allerdings darf man auch nicht die Versuche minimalisieren, die zur Errichtung sog. konsoziativer Regierungen führen sollten. Im Zusammenhang mit dem aufbrechenden ethnischen Pluralismus ist natürlich auch der Versuch zu erwähnen, dieses grundlegende afrikanische Problem durch föderative Strukturen oder Dezentralisierung zu lösen, wie dies z. B. nicht nur in Nigeria, sondern auch in Äthiopien und Südafrika versucht wurde. Häufig wird zwischen Tribalismus und ethnischem Pluralismus nicht genug unterschieden.

Die Untersuchungen messen immer wieder die neuen Regierungsformen am englischen oder französischen Staatsmodell, obschon gerade sowohl in Südafrika als auch in Äthiopien das kanadische und das bundesdeutsche Modell eine größere Rolle gespielt haben. So spricht man auch in Südafrika nicht mehr von der „Rule of Law“, sondern vom „Rechtsstaatsprinzip“. Auch hinsichtlich der Einräumung von unmittelbaren Verfassungsrechtsbehelfen (Verfassungsbeschwerde) wird nur der Vergleich zum Ombudsmann oder zum Amparo-Prinzip gezogen, die Individualbeschwerde nach Art. 93 Abs. 1 Nr. 4a des Grundgesetzes oder die Menschenrechtsbeschwerde nach der Europäischen Menschenrechtskonvention nicht oder doch zu wenig erwähnt. Die Destabilisierung afrikanischer Staaten etwa Zaire, Angola, Burundi - und die unsagbaren aber folgerichtigen Erscheinungsformen des Genozids werden nicht beschönigt. 
So darf man dennoch von der Entstehung und Entwicklung eines afrikanischen Konstitutionalismus sprechen. Dieser allerdings hat es schwer, die neuen autochthonen Kräfte zu integrieren. So ist das Buch eine wertvolle Ergänzung und Weiterführung des Standardwerks „Il Diritto Africano” von Rudolfo Sacco.

Heinrich Scholler, München

\section{Søren David}

\section{Die Verteilung der Gesetzgebungskompetenzen im südafrikanischen Verfassungsrecht} Nomos Verlag, Baden-Baden, 2000, 322 S., DM 98,--

Der Aufbau einer Verfassung - und als eines ihrer Kernstücke die Verteilung der Gesetzgebungskompetenzen - ist nicht zuletzt Spiegelbild der gesellschaftlichen und politischen Verhältnisse in ihrem Geltungsbereich. Dieser Zusammenhang, der Davids Arbeit gleichsam wie ein roter Faden durchzieht, wird anhand der wechselnden Einflüsse bis hin zum Inkrafttreten der endgültigen südafrikanischen Verfassung im Jahre 1997 eindrucksvoll deutlich gemacht. Dabei ist der Entwicklungsprozeß in Südafrika wegen der verschiedenen - auch rechtlichen Einflüsse - der unterschiedlichen Bevölkerungsgruppen und der nach wie vor gegebenen Aktualität der verfassungsmäßigen Lösungen besonders interessant. Dementsprechend spannend liest sich auch Davids Dissertation, die neben einer umfangreichen historischen Betrachtung auch eine dezidierte Analyse der Verfassungsverhandlungen zur Interimsverfassung von 1994 und der endgültigen Verfassung beinhaltet.

Das Buch besteht im wesentlichen aus drei Teilen, denen in einem vierten Kapitel eine abschließende Darstellung der Ereignisse seit Inkrafttreten der endgültigen Verfassung angehängt ist. Dabei bilden die Gesetzgebungskompetenzen der Provinzen durchgängig den Mittelpunkt der Betrachtung, die vor allem in Abgrenzung zu den Kompetenzen der nationalen Ebene, mit zunehmender Bedeutung des local government besonders in der endgültigen Verfassung aber auch in Gegenüberstellung zu den Kompetenzen der Kommunen erfolgt.

Das erste Kapitel widmet sich der Entwicklung der Gesetzgebungskompetenzen von der Gründung der Südafrikanischen Union im Jahre 1909 bis zum Ende der Apartheidpolitik im Jahre 1990. Im South Africa Act, der Gründungsakte der Südafrikanischen Union, welche den vier zuvor voneinander unabhängigen Kolonien erstmals eine nationale Autorität unter starkem britischen Einfluß vorschaltete, wurde eine weitgehende Souveränität des nationalen Parlaments nach Vorbild des britischen Westminster-Systems favorisiert - nicht zuletzt um die Befugnisse der Judikative einzudämmen und zur Kontrolle der als Bedrohung empfundenen schwarzen Bevölkerung (S. 33 f.). Den Provinzen blieben lediglich untergeordnete Kompetenzen, die teils durch sog. entrenched clauses kodifiziert, teils 
ungeschrieben waren (S. 40 ff.). Die Umgestaltung des Kompetenzengefüges mit Beginn der Apartheidpolitik geht auf andere politische Motivationen zurück. Sauber legt David dar, wie das geographische Kriterium zur Allokation provinzialer Kompetenzen durch ein ethnisches ergänzt wurde. Dies führte zu einer umfassenden Umstrukturierung der provinzialen Gebietskörperschaften, die schließlich in die Schaffung der Homelands sowie der scheinselbständigen $T B V C$-Staaten (Transkei, Bophuthatswana, Venda, Ciskei) mündete. Die damit verbundene Kompetenzverschiebung, so weist David zutreffend nach, ging maßgeblich zulasten der Provinzen, während die nationale Einflußnahme trotz der teilweisen formalen Unabhängigkeit faktisch im wesentlichen bestehen blieb. Zusätzlich werden anschließend die Kompetenzen der nicht geographisch separierbaren Bevölkerungsgruppen der Indischstämmigen und der Farbigen (Coloureds) untersucht, die aber über Vorschlagsund Beratungsrechte nicht hinausgingen. Im weiteren stellt David dar, wie das Prinzip der Selbstverwaltung in eigenen Angelegenheiten mit zunehmender Dauer immer klarer zum Machterhalt der regierenden National Party im Sinne eines divide et impera instrumentalisiert wurde und mit der Vereinigung aller Bevölkerungsgruppen im sog. Drei-KammerParlament durch die Verfassung von 1983 schließlich auch formal scheiterte (S. 58 ff.). Im Zuge der zunehmenden Machtkonzentration in der Person des Staatspräsidenten wurden die Provinzparlamente 1986 aufgehoben und ihre Kompetenzen ihm unterstehenden Verwaltern übertragen. Damit wurde gleichzeitig eine maximale Kompetenzverschiebung auf die nationale Ebene zulasten der Provinzen erreicht.

In seinem zweiten Kapitel widmet sich der Verfasser den Veränderungen, welche sich bei der Zuordnung der Gesetzgebungskompetenzen nach der Abkehr von der Apartheidpolitik im Jahre 1990 bis zum Inkrafttreten der Interimsverfassung im Jahre 1994 ergeben haben. Hierbei geht David detailliert auf die Positionen der maßgeblichen Parteien in den Verhandlungen im Rahmen der Convention for a democratic South Africa (CODESA) und des nachfolgenden Multi-Party Negotiating Process (MPNP) ein. Verständig würdigt er die politischen Notwendigkeiten, die insbesondere darin bestanden, extremere Gruppierungen durch Zugeständnisse in die weiteren Verhandlungen zur endgültigen Verfassung einzubinden. Die Unterschiedlichkeit der Forderungen macht deutlich, daß die Frage der vertikalen Gewaltenteilung von den Akteuren als zentraler Aspekt für die Gestaltung des neuen Machtgefüges betrachtet wurde. Es folgt eine umfassende Analyse der verschiedenen Kompetenzen auf nationaler und provinzialer Ebene, die jeweils den entsprechenden Begrifflichkeiten des deutschen Verfassungsrechts zugeordnet werden. Im Ergebnis schließt sich David mit guter Begründung der wohl herrschenden Meinung an, daß die Interimsverfassung trotz substantieller Besserstellung der Provinzen allenfalls als quasi-föderal bezeichnet werden kann (S. 158 ff.).

Den Schwerpunkt der Arbeit bildet sicherlich das dritte Kapitel, in dem sich der Verfasser eingehend der endgültigen Verfassung, welche schließlich nach dem Zweiten Zertifikationsurteil des Südafrikanischen Verfassungsgerichts 1997 in Kraft trat, widmet. Ausgehend von den Vorgaben durch die Verfassungsprinzipien der Interimsverfassung lotet David behutsam die gegebenen Spielräume aus und vollzieht eingehend den Gang der 
Verfassungsverhandlungen in der Constitutional Assembly nach. Gerade in der Frage der vertikalen Gewaltenteilung schieden sich auch diesmal die Geister, zumal der dominierende ANC zur Abwehr möglicher Obstruktionen durch nicht ANC-regierte Provinzen eine starke nationale Ebene befürwortete. Die überwiegende Mehrheit der übrigen Parteien favorisierte jedoch zur Wahrung ihrer jeweiligen Eigenständigkeit eine Stärkung des föderalen Elementes. Dieser Interessengegensatz führte schließlich zu einem Auszug der Inkatha Freedom Party des Zulu-Führers Buthelezi aus der Constitutional Assembly und damit zu einer zeitweiligen erheblichen Destabilisierung des Verfassungsgebungsprozesses. Die Einigung der übrigen Parteien, die durch das Erfordernis der vom Verfassungsgericht zu überprüfenden Übereinstimmung mit den Verfassungsprinzipien der Interimsverfassung noch erschwert wurde, brachte eine Fülle hochkomplizierter Kompetenzregelungen mit sich. Der Verfasser nimmt auch hier eine umfassende Zuordnung vor und scheut sich insbesondere auch nicht, das Geflecht aus ausschließlichen und konkurrierenden Kompetenzen samt der verschiedenen Ausnahmevorschriften wie Konfliktlösungsregelungen und Vorrangklauseln in klarer Darstellung zu entwirren und ins Verhältnis zu setzen. Einmal mehr überzeugt die Darstellung durch Übersichtlichkeit und eine unmißverständliche Einordnung in die einschlägige deutsche Verfassungsterminologie. Am Ende wird noch kurz auf die Zukunft der Volksstaatsidee und die neuen Kompetenzen des kommunalen local government, die abermals ganz überwiegend auf Kosten der Provinzen geschaffen wurden, eingegangen (S. $250 \mathrm{f}$.).

So wundert es denn auch nicht, daß David in seinem kurzen vierten Kapitel, welches die Verfassungswirklichkeit nach der Zertifizierung der endgültigen Verfassung durch das südafrikanische Verfassungsgericht zum Inhalt hat, in Bezug auf die Provinzen ein eher nüchternes Bild zeichnet. Es scheint, daß die substantielle Verminderung der Kompetenzen in der endgültigen Verfassung zu einer in Lethargie mündenden Resignation der Provinzparlamente geführt hat, die mit einer fast vollständigen Verdrängung aus der öffentlichen Wahrnehmung einhergeht.

Die Arbeit besticht durch eine umfassende und verständige Würdigung der rechtlichen und politischen Parameter, welche für die Abgrenzung der Gesetzgebungskompetenzen unter den verschiedenen Verfassungen von Bedeutung sind. Dabei hat der Autor die einschlägige Rechtsprechung und Literatur bis Ende 1999 umfassend berücksichtigt. Besondere Anerkennung verdient die detaillierte Auswertung der umfangreichen Dokumentationen zu den Verhandlungen der Interims- und endgültigen Verfassung. Trotz des erheblichen Umfangs des zu verarbeitenden Materials ist dem Autor eine schlanke und übersichtliche Darstellung dieser hochinteressanten und in gewisser Hinsicht auch einzigartigen Materie gelungen, die durch klar strukturierte Schaubilder im Anhang komplettiert wird. Wenn überhaupt Kritik geübt werden kann, so liegt sie darin, daß der Verfasser mitunter beiläufig politische Wertungen vornimmt, was den durchweg gut begründeten Stellungnahmen und Schlußfolgerungen teilweise etwas von ihrer Präzision nimmt. Dennoch vermag dies den hervorragenden Gesamteindruck der Arbeit nicht zu beeinträchtigen, die deutschen wie südafrikani- 
schen Verfassungsrechtlern, mit Rechtsvergleichung Befaßten sowie auch politisch Interessierten uneingeschränkt empfohlen werden kann.

Edzard A. Schmidt-Jortzig, Frankfurt/Main

\section{Helmut Janssen \\ Die Übertragung von Rechtsvorstellungen auf fremde Kulturen am Beispiel des englischen Kolonialrechts}

Mohr Siebeck Verlag, Tübingen, 2000, 217 S., DM 68,--

Englands Kolonialverwaltung und sein Kolonialrecht basierten im Wesentlichen auf dem Grundsatz der sog. indirect rule. Im Gegensatz zum kolonialen Antipoden Frankreich, der seine Kultur und auch sein Recht mit großer Konsequenz zu exportieren trachtete, erschien den Engländern die Bewahrung der einheimischen Rechtsordnungen und die Instrumentalisierung lokaler Herrschaftsstrukturen nützlich. Dabei spielte wohl nicht so sehr ein besonderer Respekt gegenüber den einheimischen Kulturen eine Rolle als vielmehr ein pragmatischer Ansatz, der auf ein möglichst unaufwendiges Herrschen zielte. Auch indirect rule hat freilich ihre unausweichlichen Reibungsprobleme. Zu ihnen gehört der Versuch, in den Gerichten vor Ort und daheim in England Recht unter zumindest partieller Berücksichtigung des jeweils indigenen Rechts zu sprechen. Englische (oder englisch ausgebildete) Richter entschieden Fälle, in denen es um das Verstehen ,indigener“ Rechtsordnungen ging. Die strukturell bedingten Verstehensdefizite, die dieses Unternehmen realiter prägten, sind das laut Klappentext und Einführung (S. 1) das selbst gesetzte Thema von Janssens Untersuchung. Es soll danach zunächst nicht um einen makropolitisch (durch das Kolonialrecht) gesteuerten Versuch gehen, eigene Rechtsvorstellungen zu übertragen, sondern um die rechtspraktischen Beschwernisse bei dem Versuch, einheimisches Recht zu sprechen. Freilich erweist die Lektüre alsbald, dass Janssens Arbeit sich in der Ausführung nicht auf das Thema das „Begreifens“ beschränkt. Letztlich schreibt er doch in weiten Teilen - was der Titel im Übrigen durchaus nahe legt - über Rechtsexport, sei es im Landrecht, sei es bei der Auslegung des Rechts der „Islamischen Frommen Stiftung“. Ungeachtet der hiermit verbundenen partiellen Inkonsistenz zwischen präsentiertem Erkenntnisziel und Untersuchungsgang ist jedoch, insofern sei ein Stück der Bilanz hier schon vorangestellt, ein Buch entstanden, dessen Lektüre sicher lohnt.

Schon der Aufbau der Arbeit ist gut durchdacht. Janssen gliedert sie in drei Teile, die mit „Gerichte“, „Recht“ und (etwas diffus) „Kultur“ überschrieben sind. Im juristischen Darstellungen neigt man hierzulande wohl üblicherweise dazu, das Recht vor den Gerichten zu behandeln, für das hier behandelte Thema ist die Umkehrung aber äußerst sinnvoll: Richter prägen das englische Recht, und insbesondere für den Kolonialbereich macht es viel Sinn, 
den Richter darstellerisch vor das Recht zu stellen. Diese Herangehensweise dokumentiert zudem den historisch-soziologischen Ansatz der Arbeit, die eine im Wesentlichen abgeschlossene Phase der Rechtsentwicklung (mit allerdings fundamentalen Gegenwartskonsequenzen), nicht theoretisch-dogmatisch, sondern in ihrer Lebenswirklichkeit darstellt.

Der erste Teil über die Gerichte gliedert sich in Kapitel über den Privy Council, Gerichte vor Ort in den Kolonien sowie die Richter. Janssen stellt dar, wie sich der Privy Council schrittweise zu einem Gericht entwickelt hat, dessen Aufgabe gänzlich auf das Recht der Kolonien bzw. Commonwealth-Staaten bezogen ist. Die Gerichte in den Kolonien selbst haben sich demgegenüber aus einer Art Beleihung der Kaufleute heraus entwickelt. Während der Privy Council insgesamt über die Zeit hinweg sehr „englisch“ geblieben ist lediglich ein Sitz wurde schließlich zu einem indischen Erbhof - wurden die Gerichtsinstanzen in den Kolonien sukzessive auch mit ,indigenen“ Richtern beschickt. Den Anfang machten hier freilich Kolonien wie Australien und Neuseeland (wo die „Indigenen“ nicht etwa Aborigines oder Maori sind, sondern Nachkömmlinge der ersten Einwanderer) und im Übrigen sind es zunächst vor allem die unteren Instanzen. Die Rechtsprechung der höheren Gerichte bleibt ebenfalls englisch geprägt, zumal hier „Indigene“ allenfalls nach einer vollständigen Ausbildung im englischen Recht Zugang zur Richterbank finden. Ein Refugium für einheimisches Rechtsdenken in den Kolonien sind freilich die sog. native courts (customary courts, local courts), in denen einheimische Autoritäten (die vielleicht bisweilen erst durch die ihnen eingeräumten Zuständigkeiten zu solchen wurden) unter variierende intensiver kolonialer Aufsicht Recht sprachen. Solche Gerichte bestehen in vielen Gebieten des ehemaligen Empire noch heute und ihre Einbindung in das staatliche Rechts- und Justizsystem ist nach wie vor schwierig. Janssen beschränkt sich hier m.E. auf allzu knappe Andeutungen (S. 38 f.).

Der zweite Teil über Recht (S. 56 ff.) besteht aus einem einleitenden Kapitel über „Anwendbares Recht“ und zwei Fallstudien, namentlich dem Landrecht (S. 86 ff.) und der Behandlung der „Islamischen Frommen Stiftung“ (S. 135 ff.). Bei der Frage des anwendbaren Rechts setzt Janssen bei der Art des Souveränitätserwerbs an. Ob die Gegenüberstellung eroberter und abgetretener Gebiete einerseits sowie der besiedelten Gebiete andererseits für die grundsätzliche Frage die Einführung des englischen Rechts als Ganzes allerdings im Ergebnis die Bedeutung hatte, die ihr traditionell und auch bei Janssen zugeschrieben wird, erscheint zweifelhaft. Auch die entwickelteren Völker, die man entdeckte (wie die neuseeländischen Maori oder viele nordamerikanische Indianerstämme) wurden unter koloniales Kuratel gestellt. Auch ihnen gegenüber prävalierte zumeist das Interesse der weißen Zuwanderer. Auf ihr eigenes Recht ließ man sich vor allem ein, wenn sie untereinander stritten, weiße Interessen also nicht berührt waren (vgl. zu diesem Aspekt auch S. 111 am Beispiel Rhodesiens) oder ggf. auch, wenn einzelne ,weiße“ Aktionen den Bogen im Umgang mit den Einheimischen gefährlich überspannt hatten. Im Grundsatz gewann England Rechtsherrschaft also unabhängig vom Erwerbstitel. Für den Zeitraum der Inbesitznahme lässt sich nicht übersehen, dass die historischen Vorgänge zum Teil eher unbekümmert von rechtlichen Fragen verliefen und die Gerichte ex post Erklärungsmuster fin- 
den mussten. Unwichtig wird die Erwerbsart durch diesen Vorbehalt freilich nicht, denn wo die Engländer zivilisatorische Strukturen zu erkennen glaubten und dementsprechend nicht von einer „Besiedelung“ ausgingen, war die Grundlage für indirect rule unmittelbar gegeben. Und wo Verträge geschlossen wurden, haben diese mit mancher Einschränkung und Verspätung zum Teil doch noch erhebliche Bedeutung entfaltet. In einer skrupulöser gewordenen Weltgesellschaft erlauben sie es den Indigenen, einige Nischen für ihre Existenz zu erstreiten. Von Walfangrechten bis hin zu Kasino-Privilegien reicht das, was sich aus einschlägigen Verträgen ableiten lässt. Aber das sind oft moderne Entwicklungen.

Die Ausführungen zum Landrecht fallen, wie schon angedeutet, ein wenig aus dem selbst gesteckten Thema der Arbeit heraus. Hier geht es nicht so sehr um Verstehensprobleme bei der Anwendung fremden Rechts, sondern schlicht um Rechtsexport. Janssen beschreibt (instruktiv) die Grundlagen des feudalen englischen Landrechts, ihre Einführung in den Kolonien sowie den Versuch, indigene Besitzansprüche in das System der titles einzuführen. Dabei greift er auch territorial und temporal weiter aus als in den übrigen Untersuchungsteilen und behandelt die Entwicklung z.B. in den USA, Kanada, Neuseeland und Australien tendenziell bis in die Gegenwart hinein. Die hier angeschnittenen Fragen sind, auch wenn mit der eigentlichen Fragestellung der Arbeit nur partiell verbunden, schon wegen ihrer hohen Praxisrelevanz von großem Interesse. Allerdings ist die Darstellung im Detail recht kursorisch und lässt - obwohl grundsätzlich Gegenwartsprobleme einbeziehend und den Stand des 31.12.1998 reklamierend (Vorwort) - wichtige neuere Entwicklungen außer Betracht. So schließt die Darstellung zu Australien mit der Mabo-Entscheidung des High Court of Australia und lässt die wichtigen Folgeentscheidungen der 90er Jahre (insb. „Wik“) ausgeblendet. Für Kanada fehlt ein Hinweis auf die bahnbrechende Entscheidung des Supreme Court in Delgamuukw v. British Columbia vom 1.12.1997. Gerade diese Entscheidung wäre für Janssens Thema interessant gewesen, geht es hier doch gerade nicht nur um die Art und Weise der Integration indigener Ansprüche in das englisch geprägte title-System, sondern zudem um „Verstehensprobleme“ im eigentlichen Sinne, nämlich die Frage, wie indigene Landrechtsvorstellungen illiteraler Gesellschaften vor Gericht zu beweisen sind (konkret hat der Supreme Court festgestellt, dass auch oral history zu berücksichtigen ist und damit den restriktiven Ansatz der Vorentscheidung korrigiert).

Als Fallbeispiel für Fehlverständnisse indigenen Rechts durch englische Richter greift Janssen die islamische Fromme Stiftung heraus. Auch hier stellt sich nach Lektüre seiner Darstellung aber die Frage, ob es hier wirklich um ein „Verstehensproblem“ geht. Janssen selbst zeigt auf, dass die Entscheidung von einem sehr spezifischen Grundverständnis des maßgeblichen Richters im Privy Council über ,,vernünftiges“ Recht geprägt ist. Möglicherweise ging es also im vorliegenden Fall weniger darum, fremdes Recht zu erkennen, als vielmehr die Spielräume zu nutzen, die das fremde Recht bietet, um eigenen Vorstellungen (und sei es in Indien) zur Geltung zu verhelfen. Der Fall ist insofern natürlich interessant, erinnert aber noch einmal daran, dass Janssen eigentlich Begreifensprobleme behandeln 
wollte. Hierfür eignet sich das Beispiel vielleicht nicht (zumal die richterliche Fehlinterpretation durch einen Gesetzgebungsakt alsbald wieder korrigiert wurde).

Der abschließende Dritte Teil über „Kultur“ gliedert sich in Kapitel über Werte (S. 153 ff.) sowie „Staatliche Gerichtsbarkeit und Schriftkultur“ (S. 173 ff.). In der Sache handelt es sich um die kritische Darstellung der philosophischen und methodischen Grundlagen des Kolonialrechts. Besonderes Augenmerk widmet Janssen dabei rechtsphilosophisch dem Einfluss der rechtsevolutionistischen Theorie Henry Maines (S. 164 ff.) und rechtsmethodisch der Bedeutung der Präzedenzmethode (S. 183 ff.). Insgesamt zeigen die Ausführungen die Grenzen auf, denen das „Sich-Einlassen“ auf fremdes Recht unterlag, wobei es wieder nicht nur um Grenzen des Verstehens geht, sondern auch um Fragen der Konkordanz mit eigenen Wertungen. Auch im englischen System der indirect rule ist neben den durch „Übersetzungsprobleme“ verursachten Modifikationen ein bewusster Rechtskolonialismus unübersehbar. Mancher Eingriff in einheimische Gepflogenheiten (etwa im Bereich der Sexualmoral) mutet heute schlicht als intolerant an und ist Ausdruck des europäischen Zeitgeistes, andere Einwirkungen (Bekämpfung der Sklaverei) erscheinen demgegenüber modern. Vergangenes zu bewerten, ist oft schwierig.

$\mathrm{Zu}$ kritisieren an der Arbeit Janssens ist abgesehen davon, dass die eigentlichen Fragen des „Begreifens“ im Sinne der kognitiven Grenzen des Verstehen-Könnens etwas beiläufig erwogen werden, dass sie sich in wichtigen Teilen weitgehend auf jüngere Sekundärliteratur zu stützen scheint. Unter gesonderter Überschrift ausführlich einen indischen Richter (Ameer Ali) im Judicial Committee zu beschreiben, der viel publiziert habe, ohne auch nur einen einzigen Nachweis zu diesen Publikationen zu geben (S. 46 ff.), erscheint z.B. etwas unsorgfältig. Hier und an manch anderer Stelle hätte man sich im Übrigen etwas mehr Vertiefung vorstellen können. Etwas bedauerlich ist im Übrigen, dass Janssen die Wirkungen des Rechtskolonialismus (mit Ausnahme des Landrechts) nicht zumindest mit einigen Andeutungen über die Unabhängigkeit hinaus verfolgt hat. Der Schwierigkeit, einheimische Traditionen richtig zu verstehen, sehen sich Richter in zahlreichen Staaten des ehemaligen britischen Kolonialreichs noch heute vielfältig gegenüber. Die Beschränkung auf das Historische ist natürlich zu respektieren, aber es wäre (auch über den gut untersuchten Bereich des Landrechts hinausgehend) interessant gewesen, zu erfahren, wie sich die Übertragung von Rechtsvorstellungen nach Rückerlangung der Unabhängigkeit, zumal in den von Janssen fokussierten Gebieten Indien und Goldküste, ausgewirkt hat.

Trotz der erwähnten Kritikpunkte hat Janssen ein interessantes und lesenswertes Buch geschrieben. Er beschreibt die Friktionen, die sich bei der Einbeziehung indigenen Rechts in die staatliche Judikatur ergaben, in stilistisch angenehmer Form (zurecht betont das Vorwort von Janssens Doktorvater Großfeld das ,erzählerische Niveau“). Gerade für den deutschen Leser ist das Buch auch insofern sinnvoll konzipiert, als die rechtshistorischen Hintergründe des englischen Rechts in den thematisch relevanten Bereichen (Entstehung und Entwicklung des Privy Council, des Landrechts etc.) instruktiv beschrieben werden. Wer sich künftig etwa mit Fragen des Legal Pluralism und dem Status ,,indigenen“ Rechts 
im Bereich des Commonwealth beschäftigt, kann sich bei Janssen über manche historische Hintergründe heutiger Problemlagen orientieren.

Jörg Menzel, Bonn

\section{Heinrich Wilms}

\section{Ausländische Einwirkungen auf die Entstehung des Grundgesetzes}

Verlag W. Kohlhammer, Stuttgart / Berlin / Köln, 1999, 341 S., DM 148,--

„Nirgendwo wird bestritten, daß das Grundgesetz durch die alliierten Besatzungsmächte sowie durch Verfassungsrecht und Ideengeschichte anderer Länder beeinflußt ist. Keine Einigkeit herrscht jedoch über Art und Umfang dieser Einflüsse sowie über deren Bewertung.“ - mit diesen Worten begründet der Konstanzer Professor für Öffentliches Recht, Rechtsphilosophie, Völker- und Europarecht Heinrich Wilms auf S. 1 der Einleitung die Fragestellung, die seiner pünktlich zum 50-jährigen Geburtstag des Grundgesetzes erschienenen verfassungsrechtlichen Monographie zugrunde liegt. Wilms hat sich in dieser Untersuchung, die viele bisher nicht publizierte, umfangreiche Materialien und Dokumente über die Arbeit des Parlamentarischen Rates erstmals auswertet, einem Forschungsdesiderat gewidmet, denn eine speziell die ausländischen Einflüsse bei der Entstehung des Grundgesetzes fokussierende Arbeit fehlte bislang. Das vorliegende Werk soll den Auftakt zu einer mehrbändigen Reihe zur neuesten deutschen Verfassungsgeschichte darstellen und will insbesondere auch einen Beitrag dazu leisten, die anläßlich der deutschen Wiedervereinigung erneut aufgekeimten Legitimitätsdiskussionen um das nach seiner ursprünglichen Konzeption sowohl räumlich als auch zeitlich Übergangscharakter tragende Grundgesetz beenden zu helfen und zugleich die Einsicht zu fördern, daß das Grundgesetz Bewahrungswert besitze.

Die Arbeit gliedert sich in vier quantitativ verschieden gewichtete Hauptteile: A. Der Einfluß ausländischer Mächte auf die Entstehung des Grundgesetzes (S. 9-83), B. Die Frankfurter Dokumente und ihr Einfluß auf die Arbeit des Parlamentarischen Rates (S. 85-96), C. Die Einflüsse ausländischen und internationalen Rechts auf die Entstehung des Grundgesetzes (S. 97-192) und D. Die Militärgouverneure und der Parlamentarische Rat (S. 193275), wobei sich jeweils Zusammenfassungen anschließen, die sich auch als Orientierung über bzw. Einstimmung in die Hauptteile lesen lassen. Die gesamte Darstellung ist durch einen sorgfältigen Fußnotenapparat belegt, und die den Kapiteln vorangestellten Literaturübersichten ermöglichen dem an Detailfragen interessierten Leser einen schnellen Überblick über das einschlägige deutsche, aber auch englische und in geringerem Maße französische Schrifttum.

Ohne dabei das Vollständigkeitspostulat verfechten zu wollen oder zu müssen, stellt der Verfasser im ersten Teil seiner Arbeit diejenigen Stationen der Vorgeschichte des Grundge- 
setzes in ihren historischen Bezügen dar, die für das Verständnis des Zustandekommens der Frankfurter Dokumente zutreffend als unerläßlich angesehen werden. In einer faktenreichen Darstellung wird deutlich, daß die in den Frankfurter Dokumenten enthaltenen grundlegenden Vorgaben für jede Verfassungsdiskussion einem spezifischen Entstehungsprozeß unterlagen, der durch den unüberbrückbaren Ost-West-Gegensatz auf den Nachkriegskonferenzen der Siegermächte und die Verhandlungen der Westalliierten in Zusammenarbeit mit den Benelux-Staaten auf der Londoner Sechs-Mächte-Konferenz (S. 46-58) vom 23. Februar bis 5. März und vom 20. April bis 1. Juni 1948 gekennzeichnet ist. Als wesentlicher Inhalt dieser Konferenz wird nicht der Inhalt der Londoner Empfehlungen in Gestalt der Frankfurter Dokumente, sondern die Entscheidung zur Errichtung einer deutschen verfassunggebenden Versammlung festgehalten. Daß die Frankfurter Dokumente den Ministerpräsidenten der Westzonen ohne die Protokolle der Londoner Konferenz übergeben worden waren, führte auf der sogenannten Koblenzer Rittersturzkonferenz (8.-10. Juli 1948) zu der politisch realitätsfernen Auffassung, die Deutschen hätten echte Verhandlungsspielräume über den Inhalt der Frankfurter Dokumente. Nach Wilms wird die Rittersturzkonferenz in der Literatur irrtümlich als bahnbrechend auf dem Weg zur Entstehung des Grundgesetzes gewertet, werde dabei doch übersehen, daß diese angesichts der gravierenden Fehleinschätzung der Ministerpräsidenten über den tatsächlich geringen Handlungsradius beinahe gescheitert wäre. Erst die sogenannte zweite Niederwaldkonferenz vom 21.22. Juli 1948 soll den maßgeblichen Durchbruch auf dem Weg zum Grundgesetz vorbereitet und erst die sogenannte Frankfurter Schlußkonferenz die endgültige Einigung erzielt haben, eine neue deutsche Verfassung zu schaffen. Auf dieser Konferenz vermochten die Deutschen gegen die Vorstellungen der Alliierten die Bezeichnung „Parlamentarischer Rat“ statt der geforderten Bezeichnung ,verfassunggebende Versammlung“ und statt „Verfassung“ die Bezeichnung „Grundgesetz“ durchzusetzen. Als weitere Errungenschaft stimmten nur die Abgeordneten der Landesparlamente und nicht das Volk unmittelbar über das Grundgesetz ab.

Im zweiten Hauptteil wird der Einfluß der Frankfurter Dokumente auf die Arbeit des Parlamentarischen Rates untersucht. Bewußt hat der Verfasser diesen Hauptteil mit rund zehn Seiten vergleichsweise besonders schmal gestaltet, kommt er doch zu dem dann am Ende der Arbeit in Thesen aufbereiteten Ergebnis, daß den Forderungen der Frankfurter Dokumente nach Demokratie, Föderalismus, angemessener Zentralinstanz und Garantie von Recht und Freiheit kein signifikanter Einfluß beizumessen ist, da diese Zielvorgaben für Staatsstrukturprinzipien mit den originären Vorstellungen des Parlamentarischen Rates kongruierten (S. 308). Ursächlich für den weitgehend fehlenden Einfluß war dabei vor allem auch der mangelnde Konsens der Westalliierten über die Staatsstrukturprinzipien. So ließ sich das föderale System Englands nur bedingt mit demjenigen der USA vergleichen, und Frankreich als Prototyp des Zentralstaats formulierte extrem föderalistische Zielvorstellungen, denen sich weder die Engländer noch die Amerikaner unterordneten. Den eigentlich nennenswerten Einfluß auf das Grundgesetz nahmen die alliierten Verbindungsoffiziere und die Memoranden der Militärgouverneure. Diese durchgehend in den Haupt- 
text integrierten zeitgenössischen Dokumente und Zitate führen zu einem gesteigerten Grad an Authentizität und erlauben dem kritischen Leser, die Wertungen und Thesen Wilms zu überprüfen und gegebenenfalls durch eigene zu ersetzen.

Der dritte und umfangreichste Hauptteil ist das eigentliche Herzstück der Untersuchung, an dessen Beginn auf S. 99 die den Leser beschäftigende methodische Frage geklärt wird, was überhaupt und - insoweit für die weitere Darstellung grundlegend - unter „Einfluß“ ausländischen und internationalen Rechts verstanden werden soll, nachdem die Begriffskonturen bereits auf S. 7 skizziert wurden. Unter „Einfluß“ will Wilms nicht allein die wortgetreue Übernahme einer Norm aus einer ausländischen Verfassung oder einem internationalen Vertrag verstehen, sondern vielmehr auch diejenigen Bezugnahmen auf ausländisches Recht, die Argumentationshilfen für oder wider die Etablierung einer Norm liefern. Die etwa 15.000 Seiten umfassenden Protokolle des Parlamentarischen Rates (S. 298) sind dabei beredtes Zeugnis der intensiven Prüfung jedes einzelnen Grundgesetzartikels in den Fachausschüssen des Parlamentarischen Rates bis hin zu den insgesamt 12 Lesungen im Plenum. Aus der fundierten Darstellung des im Ansatz wohl bereits jedem Studierenden der Rechtswissenschaft bekannten Herrenchiemseer Verfassungsentwurfs als einer Arbeitsgrundlage des Parlamentarischen Rates (S. 100-118), des Einflusses auf die Einzelberatungen des Parlamentarischen Rates (S. 119-182) mit einem deutlichen Schwerpunkt auf dem Grundrechtskatalog (S. 133-152) und schließlich der Bedeutung des ausländischen Verfassungsrechts in der Weimarer Reichsverfassung, der Reichsverfassung von 1871 und dem bekanntlich niemals in Kraft getretenen Reichsverfassungsentwurf von 1849 (S. 182-187) seien nur drei Beispiele für die Rezeption ausländischen Verfassungsrechts vorgestellt, die zugleich zu einer vertiefteren Lektüre der vorliegenden Untersuchung anregen mögen. Die Ewigkeitsgarantie in Artikel 79 Abs. 3 GG entstand in Anlehnung an Artikel 94 der französischen Verfassung der Vierten Republik, der republikanische Regierungsformen einer Verfassungsänderung entzieht. Dabei ist Artikel 79 Abs. 3 jedoch keinesfalls eine bloße Adaption, denn er nimmt die Grundsätze der Artikel 20 und Artikel 1 GG in die Unabänderlichkeitsklausel auf. In ähnlicher Weise hatte bei den Normen über das Bundesverfassungsgericht der US-Supreme Court, gekennzeichnet durch seine primären Aufgaben als Bundesrevisionsgericht, eine Vorbildfunktion, wobei Wilms hier einem Forschungsinteresse nachgeht, über das er auch schon an anderer Stelle publizierte (vgl. Wilms, „Die Vorbildfunktion des United States Supreme Court für das BVerfG“, NJW 1999, 1527-1529). Die durch den vom US-Supreme Court im Jahre 1803 im Fall Marbury vs. Madison begründete Rechtsprechung, mit der das konkrete Normenkontrollverfahren - nach deutscher Terminologie eigentlich eine Inzidentprüfung - eingeführt wurde, stand Pate bei den allerdings deutlich weiterreichenden Entscheidungen des Parlamentarischen Rates für die Regelungen der abstrakten Normenkontrolle in Artikel 93 Abs. 1 Nr. 2 GG und der konkreten Normenkontrolle in Artikel 100 Abs. 1 GG. Als Besonderheit für den Grundrechtsteil ist festzuhalten, daß sich alle Grundrechtsverbürgungen des Grundgesetzes an dem sogenannten Bergsträßer-Katalog orientieren, der sich seinerseits an den Entwurf zur Erklärung der Menschenrechte der UNO anlehnt. 
Im abschließenden vierten Hauptteil geht der Verfasser der Frage nach, inwieweit die Verhandlungen des Parlamentarischen Rates direkt durch die alliierten Militärgouverneure beeinflußt worden sind und gelangt zu der These, die Westalliierten wollten alles vermeiden, was das Grundgesetz als eine aufoktroyierte Verfassung hätte erscheinen lassen können (S. 311). Vor diesem Hintergrund akzeptierten die Alliierten bei den Abschlußverhandlungen über das Grundgesetz am 25. April 1949 trotz der Bedenken namentlich des Generals Clay die Regelungen über die konkurrierende Gesetzgebung, die Gesetzgebungskompetenz des Bundes zur Wahrung der Rechts- und Wirtschaftseinheit als auch die Mischform zwischen Bundes- und Länderfinanzverwaltung.

Nach dem Muster eines Filtrationsprinzips kulminiert die Arbeit auf S. 315 in sieben Abschlußthesen, deren Kernaussage ist, daß das Grundgesetz als eigenständige deutsche Leistung durch die Bezugnahme auf ausländisches Verfassungsrecht und Völkerrecht deutlich in die europäisch-amerikanische Geistes- und Verfassungstradition eingebettet ist und sich allein auf den Gebieten der Finanzverwaltung, der konkurrierenden Gesetzgebungskompetenz, der Inkompatibilität von Amt und Mandat sowie der Stellung Berlins im Grundgesetz faktische Einflüsse der alliierten Militärgouverneure widerspiegeln.

Das Werk wird neben einer Gesamtübersicht über das Schrifttum durch ein erfreulich differenziertes Register abgerundet, das nicht nur ein gezieltes Auffinden von Personen und zeitgenössischen Dokumenten, sondern beispielsweise auch einzelner Grundgesetzartikel erlaubt.

Resümierend läßt sich sagen, daß Wilms der sich selbst gestellten Aufgabe in vollem Umfange gerecht geworden ist. Jedem an der Entstehungsgeschichte des Grundgesetzes und insbesondere den ausländischen Einflußfaktoren Interessierten sei diese sorgfältig recherchierte, in flüssigem Stil verfaßte und zu eigenständigen, abgewogenen Thesen gelangende Arbeit uneingeschränkt empfohlen. Sie sollte ungeachtet ihres vergleichsweise hohen Preises in allen juristischen Bibliotheken zur Verfügung stehen.

Holger Pillau, Berlin

\section{Ulrich Fastenrath (Hrsg.)}

\section{Internationaler Schutz der Menschenrechte}

Entwicklung - Geltung - Durchsetzung - Aussöhnung der Opfer mit den Tätern

Dresdner Juristische Beiträge, Band 6

Dresden University Press, 2000, 178 S., DM 38,--

Der Band dokumentiert die aus Anlaß der Verabschiedung der allgemeinen Erklärung der Menschenrechte vor 50 Jahren von der Juristischen Fakultät der Technischen Universität Dresden gemeinsam mit amnesty international veranstalteten Ringvorlesung. Die sieben 
Beiträge schreiten das Spektrum von Titel und Untertitel aus, Wissenschaftler, Politiker und NGO-Mitarbeiter beleuchten den Gegenstand aus ihrer jeweiligen Perspektive.

Fastenrath, der auch als Herausgeber verantwortlich zeichnet, erörtert in seinem einleitenden und umfangreichen Beitrag „Entwicklung und gegenwärtige[n] Stand das internationalen Menschenrechtsschutzes“. Es gelingt ihm, die revolutionierende Wirkung, der Menschenrechte auf das Völkerrecht auf engem Raum anschaulich zu machen. Die Darstellung der Entstehungsgeschichte der allgemeinen Erklärung der Menschenrechte und des Abstimmungsergebnisses geben Fastenrath Gelegenheit, das Thema der Universalität der Menschenrechte zu erörtern.

Die Vielzahl unterschiedlicher, in verschiedenen kulturellen Zusammenhängen wurzelnder Begründungsansätze wertet Fastenrath als Zeichen für die Bereitschaft, universell geltende Menschenrechte zu akzeptieren; auch wirkten sie sich - tendenziell positiv - auf die Auslegung der menschenrechtlichen Normen aus. Den Geltungsgrund sieht er allein in der rechtlichen Normierung und (nachfolgenden) Beteiligung der Staaten; einen Rekurs auf universelle Werte, etwa die Menschenwürde, lehnt Fastenrath ab. Eine naturrechtliche Fundierung von Völkerrecht sei heute nicht mehr erforderlich. Damit begibt sich Fastenrath allerdings einer wirkungsvollen Argumentationshilfe für die Universalität der Menschenrechte; die Verengung seiner Fragestellung auf ihre universelle Geltung vermag diesen Schritt jedoch zu erklären. Universelle Geltung von Menschenrechtsnormen bedeute nicht zwingend einheitliche Interpretation und Anwendung derselben. Fastenrath macht dies an den klassischen Beispielen - Sklaverei, Frauen, Todesstrafe - deutlich und schlußfolgert, es komme - mangels menschenrechtlicher Austauschbeziehungen - darauf an, Staaten wenigsten an ihrem eigenen Menschenrechtsverständnis zu messen.

Daß hierbei auch gewisse völkerrechtliche Mindeststandards zu beachten sind - seien sie völkergewohnheitsrechtlich begründet oder als allgemeine Rechtsgrundsätze anzusehen schiebt er im Anschluß an eine gelungene und kenntnisreiche Darstellung der drei Dimensionen (oder Generationen) der Menschenrechte nach. Der abschließende Teil seines Beitrages ist Fragen der Durchsetzung von Menschenrechten gewidmet. Auch hier gibt Fastenrath eine sehr gute Übersicht, die die einzelnen Fragen trotz der notwendigen Kürze klar und für den Leser gewinnbringend behandelt.

Einige der in seinem Ausblick genannten Weiterentwicklungen haben sich inzwischen verwirklichen lassen, so das Individualbeschwerdeverfahren unter CEDAW (siehe dazu: 20 Jahre Übereinkommen zur Beseitigung jeder Form von Diskriminierung der Frau (CEDAW), Studien zu Grund- und Menschenrechten, Heft 5, April 2000, sowie Anna Golze, Die Individualbeschwerde nach dem Übereinkommen zur Beseitigung jeder Form von Diskriminierung der Frau (CEDAW), in: J. Hasse / E. Müller / P. Schneider (Hrsg.), Menschenrechte, 2001). Ob der Ausbau der verschiedenen Präventionsmechanismen die in diese gesetzten Erwartungen erfüllt hat, muß wohl eher zurückhaltend beurteilt werden (vergleiche dazu Ekkehard Strauß, Präventionen von Menschenrechtsverletzungen als Aufgabe internationaler Organisationen, Rechtsgrundlagen und inhaltliche Ansätze, 2001). 
Das Buch enthält weiterhin einen Beitrag von Christian Tomuschat zur Aufarbeitung von Menschenrechtsverletzungen durch die Wahrheitskommission in Guatemala: „Vergangenheitsbewältigung durch Aufklärung“. Diese beruht auf dem Abkommen von Oslo (23. Juni 1994), das Teil einer komplexen Friedensregelung zwischen Regierung und Guerilla ist. Tomuschat war Mitglied der Kommission, die im Frühjahr 1999 die Ergebnisse ihrer Arbeit präsentierte. Nach einem Überblick über die geschichtliche Entwicklung Guatemalas und das Mandat der Kommission schildert er ihre Arbeit und die zu überwindenden Hemmnisse. Eine offizielle Aufarbeitung des Kommissionsbericht unterblieb, wesentliche Empfehlungen wurden nicht umgesetzt. Aber die „Wahrheit“ ist offenkundig, das Geschehene bekannt. Ob die Teile der guatemaltekischen Gesellschaft sich angesichts dessen tatsächlich miteinander aussöhnen können, bleibe abzuwarten.

Otto Lagodny beschreibt ausgehend vom Fall Pinochet die „Wege zu einem Internationalen Strafgerichtshof" und erörtert in diesem Zusammenhang auch die notwendigen Rechtsänderungen in der Bundesrepublik Deutschland. Er weist dabei auf den Unterschied zwischen einer Überstellung an den IStGH und einer Auslieferung an einen anderen Staat hin.

Der Beitrag Winrich Kühnes befaßt sich mit den Friedenseinsätzen der Vereinten Nationen in einem geänderten weltpolitischen Umfeld. Ging es anfangs (nur) um die Überwachung von Waffenstillständen, so kamen später Maßnahmen hinzu, die mithelfen sollten, den zugrundeliegenden Konflikt zu beenden. Polizei und Zivilpersonal wurden in die Einsätze eingebunden. Die heutige Generation von Friedenseinsätzen - plastisch als robust bezeichnet - ist dadurch gekennzeichnet, daß der begrenzte Einsatz von Gewalt zur Sicherung der Mandatserfüllung zulässig ist. Kühne diskutiert die hiermit verbundenen Probleme und macht deutlich, welche Herausforderungen gemeistert werden müssen.

Reinhard Marx handelt über „Nichtregierungsorganisationen - Bürgerengagement und Menschenrechtspolitik“. Dabei erörtert er ihre Mitwirkungsmöglichkeiten im Rahmen der Vereinten Nationen ebenso wie die Betätigungsfelder im Nationalstaat. Gerade menschenrechtlich orientierte Nichtregierungsorganisationen haben auf beiden Ebenen noch viele Aufgaben vor sich.

Der langjährige Leiter der deutschen Delegation in der Menschenrechtskommission, Gerhart R. Baum, stellt deren „Menschenrechtspolitik zwischen Konfrontation und Kooperation" dar. Seine Tour d'horizon findet mitunter deutliche Worte, etwa wenn er für die Abschaffung der Todesstrafe, gerade auch in den USA, eintritt oder von der derzeitigen Bundesregierung ein konsequentes Eintreten für die Menschenrechte fordert.

Brillant formuliert und spannend aufgebaut evoziert der Beitrag Bruno Simmas - „Internationaler Menschenrechtsschutz durch die Vereinten Nationen“ - geradezu den engagiert Vortragenden; seine aus der Perspektive des langjährig Beteiligten geschriebene Darstellung verschweigt die Probleme nicht, benennt die wichtigsten Herausforderungen, die bald bewältigt werden müssen, und zählt hierzu auch eine intensivierte Beschäftigung mit den Menschenrechten in Erziehung und Ausbildung. Hierzu leistet das vorliegende Buch einen wichtigen Beitrag.

Norman Weiß, Potsdam 


\section{Eckart Klein (Hrsg.)}

\section{The Duty to Protect and to Ensure Human Rights}

Schriftenreihe des Menschenrechtszentrums der Universität Potsdam, Band 8

Berlin Verlag Arno Spitz, Berlin, 2000, 341 S., DM 69,--

Der Band gibt die Beiträge und Diskussionen des Colloquiums des Potsdamer Menschenrechtszentrums im Juli 1999 zum Thema Schutz der Menschenrechte gegenüber privaten Eingriffen wieder. Das Buch folgt dem namhaft besetzten Colloquium in Ansatz und Aufbau: Die Beiträge untersuchen die Schutzpflichten des Staates in verschiedenen nationalen Rechtsordnungen, in der EG/EU sowie in den regionalen und globalen Menschenrechtssystemen der EMRK, AMRK, Folterkonvention und IPBPR. Den Beiträgen folgen Kommentare und die Zusammenfassungen der Diskussionen. Die Beiträge zur nationalen Ebene behandeln staatliche Schutzpflichten im Verfassungsrecht Deutschlands (Graßhof, Sachs), der USA (Kelley), Israels (Kretzmer, Nolte) und der osteuropäischen Staaten (Brunner). In allen Rechtsordnungen waren es die Gerichte, die über die klassischen Abwehrrechte hinaus auch Schutzpflichten des Staates entwickelten. Dabei stand das Recht auf Leben im Vordergrund. Der Überblick von Brunner über die Entwicklung der Schutzpflichten in den osteuropäischen Staaten zeigt aber auch andere Ansätze, z.B. die Herleitung aus einer Umweltschutzbestimmung (S. 78 f.).

Nach der Analyse der Rechtsprechung des Bundesverfassungsgerichts (Graßhof) ist das Verhältnis der Abwehrrechte zu den Schutzpflichten inkongruent, da nicht aus jedem Abwehrrecht auch eine entsprechende Schutzpflicht bzw. ein subjektives Recht folgt (S. 43 f.). Sachs weist auf die dogmatischen Schwierigkeiten hin, die aus den Schutzpflichten folgen, z.B. wenn sie als Eingriffsermächtigung in schrankenlose Grundrechte dienen (S. 64 ff.). Sowohl Graßhof als auch Sachs weisen auf die Änderung der Funktion des Gerichts hin, die sich aus der Kontrolle der Erfüllung der staatlichen Schutzpflicht ergibt (S. 42, 69). Dies erklärt möglicherweise auch den eher niedrigen Standard, den das BVerfG für die Erfüllung der Schutzpflicht genügen läßt (S. 48) und die Argumente von Sachs für judicial self-restraint in diesem Bereich (S. 70).

Vor diesem Hintergrund ist die positive Sicht verständlich, die Kelley aus der Rechtslage in den USA gewinnt. Wegen der Betonung der föderalen Struktur der Verfassung gibt es auf Bundesebene keine Gesetzgebungskompetenz, um den Bürger vor privaten Eingriffen in seine Bürgerrechte zu schützen (S. 98 f.). Die Ratifikation des IPBPR verleiht zwar eine entsprechende Bundeskompetenz, jedoch wird nach Ansicht Kelleys die Umsetzung politisch schwierig werden. Die Verfassung legt auch den einzelnen Bundesstaaten keine Schutzpflicht auf (S. 121 ff.). Der Schutz vor privaten Eingriffen erfolgt daher aufgrund von politischen Entscheidungen in Gestalt einer Vielzahl von einzelnen Gesetzen (vor allem zum Diskriminierungsverbot). Kelley hält die Möglichkeit flexibler Lösungen, die sich daraus ergibt, für besser als die Festlegung auf Verfassungsprinzipien durch demokratisch nicht legitimiertes Richterrecht (S. 129 ff.). In ähnlicher Weise behandeln die Beiträge von Kretzmer und Nolte zum israelischen Recht die Ausgestaltung der Schutzpflichten 
durch Einzelgesetze (S. 144 ff., S 158) trotz der eher restriktiven Schutzpflichten (S. 141 f., S. 158).

Auf regionaler und globaler Ebene untersuchen die Beiträge Entwicklung, Inhalt und Grenzen der staatlichen Schutzpflichten im Rahmen der Europäischen Menschenrechtskonvention (Wildhaber, Ress, Bernhardt), der Europäischen Union (Hilf / Staebe), der Amerikanischen Menschenrechtskonvention (Kokott), der Folterkonvention (Mavrommatis, Karl) und des Internationalen Paktes über bürgerliche und politische Rechte (Klein, Dupuy).

Am wenigsten entwickelt sind nach Hilf und Staebe die Schutzpflichten auf der Ebene der EG/EU. Nach Analyse der dürftigen Vertragsbestimmungen und Rechtsprechung, vor allem der Entscheidung des EuGH im Fall Französische Landwirte, argumentieren sie dennoch für das grundsätzliche Bestehen einer Schutzpflicht der EG/EU innerhalb ihrer Kompetenzen hinsichtlich der Grund- bzw. Menschenrechte (S. 224 ff.). Man wird sehen, ob der EuGH die Grundrechtscharta zum Ausgangspunkt für eine entsprechende Entwicklung nehmen wird.

In den übrigen Beiträgen kommt der vergleichende Ansatz des Buches besser zur Geltung, da bestimmte dogmatische und praktische Probleme in allen Menschenrechtssystemen auftauchen und als roter Faden dienen können. Weitgehender Konsens besteht darüber, daß grundsätzlich aus allen Menschenrechten eine Schutzpflicht folgen kann, wobei sich Abwehrrecht und Schutzpflicht überschneiden können (S. 209, 231, 292, 321). Für Ress sind Schutzpflichten grundsätzlich nur den absolut geschützten Rechten inhärent. Jedenfalls folgt für ihn aus den absoluten, naturrechtlich begründeten Rechten eine weitergehende Schutzpflicht (S. 169 f.). Der Inhalt der Schutzpflicht läßt sich nicht als abstrakter Standard festlegen, sondern nur fallorientiert (S. 231 f., 314). Gleiches gilt für die Schranken der Schutzpflicht (S. 181, 195, 316) und für die Frage, ob sich aus Schutzpflichten auch subjektive Rechte ergeben (S. 168, 276, 316). Auffällig ist die Bedeutung der Verfahrensrechte in allen Menschenrechtssystemen, vor allem der Untersuchungspflicht des Staates (S. 170, 257 ff., 284 f., 308) und Beweislastumkehr (S. 246, 316). Konkret verlangt die Schutzpflicht in vielen Fällen außerdem strafrechtliche Sanktionen für Verletzungen durch Private (S. 173, 248, 266 ff., 293, 308). Daraus ergeben sich Probleme hinsichtlich der Rechtssicherheit und des nulla poena-Prinzips (S. 231, 316, 327).

Einigkeit besteht unter den Autoren, daß der Standard der Schutzpflicht für neue Staaten in der EMRK oder EU nicht niedriger sein soll. Bestehende Unterschiede können vielmehr im Rahmen des Bewertungsspielraums der Staaten berücksichtigt werden (S. 28, 232 f.). Weiterhin wird diskutiert, ob und inwieweit sich die Schutzpflicht über das Staatsgebiet hinaus erstreckt (S. 188, 311, 323, 327 f.).

Insgesamt bietet das Buch eine sehr gute Bestandsaufnahme zu den staatlichen Schutzpflichten auf den wichtigsten Ebenen des Menschenrechtsschutzes. Ein Schönheitsfehler ist dabei das Lektorat dieses in englischer Sprache erschienenen Bandes. Es gibt mehr als eine Handvoll Stellen, die den Eindruck vermitteln, das Buch sei nicht hinreichend Korrektur gelesen worden. Inhaltlich werden die gut gegliederten Aufsätze jedoch dem Anspruch des Buches gerecht, eine vergleichende Perspektive zu bieten. Dazu tragen auch die Zusam- 
menfassungen der Diskussionen bei. Schon jetzt bestehen divergierende Standards unter den verschiedenen Menschenrechtssystemen in Bezug auf Auslieferung und Abschiebung (S. 188 ff., 282 ff., 286). Über die Bestandsaufnahme hinaus bietet das Buch daher einen lesenswerten Ansatzpunkt für die Weiterentwicklung der Schutzpflichten und ihrer Abstimmung unter den verschiedenen Menschenrechtssystemen.

Ralph Czarnecki, Berlin

\section{Stefan Simon}

Autonomie im Völkerrecht

Ein Versuch zum Selbstbestimmungsrecht der Völker

Nomos Verlag, Baden-Baden, 2000, 149 S., DM 48,--

Die Forderung nach Autonomie seitens ethnischer Gruppen ist aktueller denn je: Nicht nur in Europa, am Beispiel des Kosovo, wird dies deutlich, sondern auch in Lateinamerika, Asien und Afrika werden die Autonomieforderungen immer lauter. Die Autonomie wird oftmals als der einzige Ausweg aus staatlicher Unterdrückung oder Bevormundung betrachtet. Die Bereitschaft der Staaten, solchen Forderungen nachzukommen, ist in der Regel mehr als zögerlich, aus bekannten Gründen: wird die Autonomie erst gewährt, liegt die Sezession nicht mehr fern, so die Befürchtung der Regierungen.

Die Frage, die Stefan Simon in seiner Bearbeitung der „Autonomie im Völkerrecht“ aufwirft, betrifft jedoch nicht die politische Forderung, sondern er untersucht vielmehr, inwieweit geltende Völkerrechtsnormen einschließlich des Völkergewohnheitsrechts, also Quellen gemäß Art. 38 I lit. a) und b) IGH-Statut, einer kulturellen Gruppe das Recht auf Autonomie gewähren können und was gegebenenfalls dessen Inhalt ist.

Mit solidem juristischem Handwerkszeug werden zunächst die vorhandenen Normen untersucht, aus denen sich ein solches Recht möglicherweise ableiten lässt. Der Aufbau erinnert allerdings zumindest in seinem ersten Teil an Untersuchungen zum Selbstbestimmungsrecht der Völker: Betrachtung einschlägiger Normen der UN-Charta (Art. 1 Ziff. 2, Art. 55), die Kapitel XI - XIII der UN-Charta (Dekolonisierungsprozesse), die „Friendly Relations"-Deklaration aus dem Jahr 1970, die Artikel 1 der Menschenrechtspakte von 1966 (vgl. den Aufbau bei Karl Doehring, in: Bruno Simma (Hrsg.), Kommentar zur Charta der Vereinten Nationen, 1991, nach Art. 1), während im darauf folgenden Abschnitt in Abgrenzung zum Selbstbestimmungsrecht der „Völker“, Minderheitenrechte und Rechte von Urvölkern näher untersucht werden. Abschließend wird das Völkergewohnheitsrecht betrachtet.

Zunächst untersucht der Autor das Recht auf Selbstbestimmung der Völker nach Art. 1 Ziff. 2 und Art. 55 der UN-Charta. Die Auslegung nach Wortlaut, Teleologie, Systematik und Historie ergibt jedoch recht schnell: Ein „Recht auf Autonomie“ lässt sich aus diesen 
Normen nicht herleiten. Insbesondere bieten die objektiv-dynamische Interpretation der Charta und der Rückgriff auf den Willen der Verfasser, welcher mangels einschlägiger Dokumente fehlschlägt, keinen Aufschluss zu einem solchen Recht.

Ergebnis der Untersuchungen zu Kapitel XI der Charta ist, dass die im Dekolonisierungsprozess entstandenen Autonomien aufgrund der besonderen Situation - Beendigung einer Besetzung des Landes durch einen kolonisierenden Staat - als eine eigene Art zu qualifizieren sind. Sie lassen sich somit nicht auf heute anzutreffende Strukturen außerhalb des Dekolonisierungsprozesses übertragen, sondern können allenfalls Beispielcharakter für die Lösung ähnlich gearteter Konflikte besitzen. Zugleich nutzt der Verfasser dieses Kapitel, um inhaltliche Ansprüche an eine funktionierende Autonomie zu formulieren: Demnach ist Autonomie nur dann als Ausfluss des Selbstbestimmungsrechts zu qualifizieren, wenn eine frei gewählte Legislative existiert und die Verfassungswirklichkeit die Selbstbestimmung in eigenen Angelegenheiten zum Ausdruck bringt.

Die nun anschließende Untersuchung der Kapitel XII und XIII der Charta, die Regelungen zu den Treuhandgebieten enthalten, dient hingegen eher der Vollständigkeit eines juristischen Gutachtens, da sie aufgrund ihrer Zielrichtung - Entlassung in die Unabhängigkeit nicht zu weiteren Erkenntnissen hinsichtlich von Autonomieregelungen führen kann.

Im Rahmen der Bearbeitung der Selbstbestimmungsartikel der Menschenrechtspakte von 1966 führt der Verfasser die Unterteilung in formelle und materielle Selbstbestimmung näher aus und definiert so, welche Gewährleistungen mit den Art. 1 IPBPR und IPWSKR $\mathrm{zu}$ verbinden sind: Formelle Selbstbestimmung als Bestimmungsmöglichkeit über den eigenen politischen Status und materielle Selbstbestimmung hinsichtlich der Ausübungsund Entwicklungsmöglichkeit von wirtschaftlicher, sozialer und kultureller Entwicklung. Es folgen Ausführungen zu dem Verhältnis dieser beiden Gewährleistungsansprüche zueinander. Ob seitens eines Staates „nur“ materielles oder aber auch formelles Selbstbestimmungsrecht zu gewährleisten ist, kann nicht allgemein entschieden werden, hängt danach von der Lage im jeweiligen Staat ab. Fazit: Ein Recht auf Selbstbestimmung lässt sich zwar aus den Artikeln 1 der Menschenrechtspakte herleiten, es ist jedoch flexibel ausgestaltet und nähert sich so Autonomieregelungen an.

Alle Arbeiten, die sich mit Autonomie bzw. dem Selbstbestimmungsrecht der Völker beschäftigen, müssen früher oder später Stellung zum verwendeten Volksbegriff beziehen, eine Problematik, die wiederum eigene Doktorarbeiten hervorgebracht hat (vgl. z.B. jüngst Bernd Roland Elsner, Die Bedeutung des Volkes im Völkerrecht, Berlin, 2000). Simon lässt es an dieser Stelle auf eine Abgrenzung der Minderheit zum Volk hinauslaufen, wobei von letzterem immer dann die Rede sein soll, wenn das zuvor herausgearbeitete formelle und materielle Selbstbestimmungsrecht ausgeübt werden kann. Minderheiten hingegen fehlt diese Fähigkeit der Ausübung, und demzufolge sollen sie sich auf den Individualrechtsschutz stützen können, um ihre Rechte geltend machen zu können. Eine gewagte These, denn wer bestimmt, wann eine Minderheit auch das formelle Selbstbestimmungsrecht ausüben kann und damit zum Volk wird? Idealerweise tut das die - vom Autor ein- 
geführte - „kulturelle Gruppe“ selbst, doch dies dürfte wohl nur auf der theoretischen Ebene funktionieren.

Nachdem sich der Verfasser der Meinung anschließt, der Minderheitenschutz umfasse ausschließlich den Individualrechtsschutz, widmet er sich dennoch im folgenden Teil den in Verträgen verankerten Minderheitenschutzrechten. Diese Darstellung macht im historischen Teil Sinn, da vor dem zweiten Weltkrieg Autonomielösungen oft für Minderheiten getroffen wurden, wohingegen die Untersuchung aktueller Schutznormen mit dem Argument gerechtfertigt wird, einige Normen - die sich an eine unbestimmte Anzahl von Minderheiten wenden - könnten zumindest einen Bezug zur Autonomie ergeben. Dafür bietet sich Art. 27 IPBPR aufgrund seines Wortlauts an. Der Verfasser arbeitet jedoch, konsequent zur bisherigen Darstellung, dessen Beschränkung auf die individualrechtsschützende Komponente heraus.

Auch der gesamte weitere Abschnitt ist gekennzeichnet von der Abgrenzung der individualrechtsgeschützten Minderheitenrechte zu Autonomierechten, die nach Ansicht des Autors ausschließlich Völkern zustehen. Und dies trotz aktueller Tendenzen - auf die er am Ende dieses Abschnitts selbst - kritisch - verweist, (S. 98) - insbesondere auch auf europäischer Ebene, die sich beispielsweise in der seit 1998 in Kraft befindlichen Rahmenkonvention des Europarats zum Schutze nationaler Minderheiten von 1995 finden. Diesbezüglich wird zutreffend festgestellt, dass sich direkte Autonomierechte im Sinne der Auslegung des Verfassers (Selbstregierungsfähigkeit) darin nicht finden lassen.

Die einzige Gruppe, der der Autor eine Art Zwitterstellung zwischen Minderheit und Volk zugesteht, sind die sogenannten „Urvölker“. Während er insoweit das Bestehen normierter Autonomierechte verneint, bejaht der Autor die Möglichkeit zur materiellen Selbstbestimmung. Ein Recht auf formelle Selbstbestimmung wird von ihm mangels vertraglicher Regelungen und mangels Staatenpraxis verneint. Der Autor verweist zwar auf die Notwendigkeit von Untersuchungen im Einzelfall, bleibt diese aber schuldig. Gerade zur Staatenpraxis hätten sich Beispiele finden lassen, wie die relativ weitgehenden Autonomieregelungen für Urvölker in Nicaragua.

Die abschließende Betrachtung zum Völkergewohnheitsrecht konzentriert sich zunächst insbesondere auf das Verhältnis der Elemente opinio iuris und Staatenpraxis zueinander. Unter Abwägung der einschlägigen Argumente spricht sich der Verfasser dafür aus, dass die opinio iuris das eigentliche konstitutive Element des Völkergewohnheitsrechts sei. Der Bezug zur Autonomie wird jedoch erst an sehr viel späterer Stelle hergestellt. Dass die Autonomie auch aus dem Völkergewohnheitsrecht hergeleitet werden kann, wird insbesondere an der „Friendly-Relations-Declaration“ aus dem Jahr 1970 festgemacht, was überzeugt.

Abschließend gibt der Autor eine kurze Übersicht anhand einzelner Beispiele über die Staatenpraxis. Die Auswahl der Autonomielösungen für die Palästinenser und im Kosovo ist deshalb angebracht, weil sie Beispiele für opinio iuris und die Zwangsmöglichkeiten im Bereich der Staatenpraxis gegenüber dem repressiven Staat darstellen. Insgesamt gerät der durchaus spannende Ausflug in die Praxis aber zu diskursiv. Dieser Eindruck verstärkt sich 
im Rahmen der Darstellung des dritten und abschließenden Beispiels der „Zigeuner“ (hier wäre der international verwendete Terminus „Sinti und Roma“ wohl angebrachter gewesen).

Zum Schluss ist folgendes anzumerken: Dem Verfasser gelingt in seiner Arbeit zum einen die Herausarbeitung der Verankerung von Autonomieregelungen im Völkerrecht und zum anderen die Einführung eines eigenen in sich stimmigen theoretischen Modells zu den Anforderungen, die an die „Autonomiefähigkeit“ einer kulturellen Gruppe zu stellen sind. Diese Dissertation ist damit für jeden Völkerrechtler, der sich mit Autonomieregelungen beschäftigt, eine Bereicherung.

Carola Hausotter, Gießen

\section{Cornelia Schmolinsky}

\section{Friedenssicherung durch regionale Systeme kollektiver Sicherheit}

Voraussetzungen und Hindernisse am Beispiel der Liga der Arabischen Staaten

Bochumer Schriften zur Friedenssicherung und zum Humanitären Völkerrecht, Band 41

Berlin Verlag Arno Spitz, Berlin, 2000, 311 S., DM 62,--

Das vorliegende Buch entstand als Dissertation im Rahmen des Graduiertenkollegs „Systemeffizienz und Systemdynamik in Entwicklungsländern: Zur Stabilität sozialer, politischer und wirtschaftlicher Ordnungen“ am Institut für Entwicklungsforschung und Entwicklungspolitik (IIE) der Ruhr-Universität Bochum und will besonders solche Leser ansprechen, die sich mit gegenwartsbezogener Forschung zum Nahen und Mittleren Osten bzw. mit Problemen der Friedenssicherung im Rahmen internationaler Organisationen beschäftigen. Es setzt bei den neuen Bedingungen der internationalen Politik nach dem Ende des Kalten Krieges an.

Das Hauptinteresse der Arbeit Cornelia Schmolinskys richtet sich auf die Frage, ob das Konzept regionaler Systeme kollektiver Sicherheit nach dem Ende des Kalten Krieges einen Beitrag zur Friedenssicherung in der arabischen Welt leisten kann.

Zunächst stellt die Autorin dar, daß die arabische Welt mit der Liga der Arabischen Staaten über eine Staatenverbindung verfügt, die nach dem Willen der Gründer und laut Vertragswerk Ansätze kollektiver Sicherheit aufweist, die auch mehrfach in der Praxis herangezogen wurde. Nach der Abgrenzung der Begriffe und Erläuterungen der unterschiedlichen theoretischen Ansätze wird jedoch deutlich, daß die Liga fast keine der Bedingungen funktionierender Systeme kollektiver Sicherheit vollständig erfüllt.

Folgerichtig stellt die Verfasserin die Frage, ob und inwieweit die von ihr aufgezeigten Mängel behoben werden könnten, kommt aber zu dem Schluß, daß bei den rechtlich-institutionellen Schwächen des arabischen Friedenssicherungssystems ansetzende Lösungsvor- 
schläge praktisch nicht durchführbar sind oder inakzeptabel wären. Ohne eine Überwindung der Interessengegensätze und eine Aussöhnung aller LAS-Mitglieder, also einer Beendigung des Mißtrauens gegeneinander, kann die schon länger anhaltende Lähmung nicht überwunden werden.

Schmolinsky analysiert in ihrer Arbeit die in der Theorie/Idee erwarteten wie aus der Praxis erfahrenen Vor- und Nachteile der Friedenssicherung durch universelle oder regional begrenzte Staatenverbindungen. Noch einmal weist sie auf die Differenzen innerhalb der LAS hin, deretwegen das den rechtlichen Statuten zugrundeliegende Konsens-Prinzip nicht recht zum Tragen kommen kann. Allerdings verfügt die LAS im Gegensatz zu anderen Regionalorganisationen dank des Ölreichtums einiger Mitglieder über ausreichende finanzielle Ressourcen. Ein anderes Spezifikum ist die besondere Aufmerksamkeit der Weltöffentlichkeit und der Großmächte für diese Region - auch diese ist dem Ölreichtum zu verdanken.

Nach dem Debakel des zweiten Golfkriegs - auf das ausführlich eingegangen wird - beobachtet sie eine zunehmende Marginalisierung hinsichtlich der arabischen, regionalen wie internationalen Politik. Trotzdem erscheint der Autorin eine Auflösung des LAS undenkbar, denn sie sich eine außerhalb der Region präsente gesamtarabische Institution und ein Symbol arabischer Einheit.

Im Praxis-Überblick reichen die Fallstudien vom seit 1945 schwelenden Kurdenkonflikt im Irak, Grenzstreitigkeiten zwischen Sudan und Ägypten 1958, dem Bürgerkrieg im Nordjemen 1962-1970 bis in zu Somalia und Algerien, um nur einige wenige Beispiele zu nennen. Dazu erklärt die Autorin, daß sich die Liga vielfach um Vermittlung bemühte und oft unterstützend $\mathrm{zu}$ einer Beilegung oder Regelung des betreffenden Streits beitrug. Es erscheint allerdings unwahrscheinlich, daß die aufgezeigten Hindernisse überwunden werden und sie international Friedenssicherung betreiben kann. Beschränkt auf die eigene Region wird sie von begrenztem Nutzen sein.

Im Anhang findet sich neben Kapitel VII der UNO-Charta und einigen Tabellen ein gutes Literaturverzeichnis. Die Arbeit ist sinnvoll eingeteilt, fleißig und solide. Sie bietet einen fundierten Einblick in die quasi eigene Friedenssicherung innerhalb der arabischen Welt, zeigt jedoch keine neuen oder ungewöhnlichen Erkenntnisse auf ihrem Sachgebiet.

Dagmar Reimmann, Tong Norton, GB 


\section{Joachim Kayser}

\section{Gegenmaßnahmen im Außenwirtschaftsrecht und das System des Europäischen Kollisionsrechts}

Eine Analyse der EU-Abwehrverordnung gegen die Auswirkungen extraterritorialer Rechtserstreckung eines Drittlandes

Studien zum vergleichenden und internationalen Recht, Band 56

Peter Lang Verlag, Frankfurt a.M., 2001, 217 S., DM 79,--

Drittland aus der Sicht des im Untertitel angeführten und in Kaysers Arbeit näher analysierten EG-Rechtsakts sind regelmäßig die USA, ihre politischen, auch mit wirtschaftlichen Maßnahmen bekämpften Gegner durchweg Staaten der „Dritten Welt“, von China über Kuba bis zu Libyen und dem Iran. Eine gewisse Sonderstellung nimmt nur der PipelineKonflikt 1982 ein, bei dem die UdSSR als mutmaßlicher Störenfried in Afghanistan 1979 und in Polen 1981 das Ziel der (Gegen-)Maßnahmen, die auf Diversifizierung ihrer Energieimporte setzenden EG-Staaten (und „Gemeinschafts“-Unternehmen) hingegen die Hauptbetroffenen waren. Kayser faßt in der in Heidelberg bei E. Jayme entstandenen Dissertation sein Thema, welches an der europäischen Reaktion auf den US Helms-Burton bzw. den d'Amato Act ansetzt, bewußt weit, geht es ihm doch darum, angesichts der ,praktische(n) Relevanz, die Gegenmaßnahmen für private Teilnehmer am Wirtschaftsverkehr haben“, diesen primär Betroffenen „orientierende Leitlinien in Rechtsfragen“ zu geben (S. 12). Nach der Einleitung - mit Ausgangspunkt, Fragestellung und Gang der Darstellung etwas redundant - befaßt sich Kayser zunächst mit „Erst“maßnahmen, auf die reagiert werden soll, d.h. primär mit den US-amerikanischen Sanktionsgesetzen gegen Kuba (Helms-Burton Act, S. 36 ff.) sowie gegen den Iran und Libyen (d'Amato Act, S. 48 ff.) aus dem Jahr 1996, die einen „bisherigen Höhepunkt im transatlantischen Justizkonflikt“ (S. 18) bildeten. Teil 2 der Untersuchung erörtert sodann, ob und in welchen Fällen es aus inländischer Perspektive geboten erscheint, ausländischen Anordnungen und Vorschriften mit extraterritorialem Regelungsanspruch Folge zu leisten. Hier werden die unterschiedlichen Ansichten zur Berücksichtigung ausländischer Eingriffsnormen auf kollisionsrechtlicher Ebene dargestellt und bewertet, wobei Kayser die Lehre von der Sonderanknüpfung präferiert, da sie ,flexible und paßgenaue Lösungen je nach Lage der Umstände des Einzelfalls“ (S. 77) ermögliche. Das Helms Burton- wie das d'Amato-Gesetz seien funktional betrachtet derartige Eingriffsnormen, denen freilich das notwendige Näheverhältnis zum Erlaßstaat fehle, so daß - nach allen hierzu vertretenen Auffassungen - eine innerstaatliche Berücksichtigung zu verneinen sei; um ,die eigenen Staatsbürger vor den faktischen Auswirkungen der häufig in solchen Gesetzen für den Fall der Nichtbeachtung vorgesehenen Sanktionen zu schützen, stellt sich stattdessen in der Rechtspraxis die Frage nach Möglichkeit und Grenzen inländischer abwehrender Gegenmaßnahmen“ (S. 90). Im dritten Teil beleuchtet Kayser also eingangs die „Unvollkommenheit einvernehmlicher völkerrechtlicher Konfliktlösungsmechanismen“ (S. 92 ff.), läßt jedoch offen, ob Art. XXI GATT überhaupt einschlägig sei (S. 95 f.). Die konstatierte „Hilflosigkeit“ (S. 98) des Völkerrechts 
führe nicht nur zum Rückgriff auf Repressalien, sondern - im Hinblick auf die Art der „Angriffsmittel“ - auch zu „Abwehrmaßnahmen, die dem internationalen Privat- und Verfahrensrecht des verletzten Staates entstammen“ (S. 98). Kayser geht dabei Schritt für Schritt einzelnen Reaktionen gegenüber Gesetzen, Exekutiv- und Judikativakten nach, mit dem eher ernüchternden Fazit, diese taugten nicht ,zu flächendeckender und effizienter Abwehr“ (S. 119), die Möglichkeiten blieben ,im Gesamtergebnis mithin gering“ (S. 120). Diese Erkenntnis führt ihn zum Hauptteil der Untersuchung, überschrieben als Darstellung und Analyse der EG-Verordnung Nr. 2271/96 des Rates (mitsamt der Gemeinsamen Aktion dieses Organs, 96/668/GASP). Der Rechtsakt stelle insgesamt gesehen das bisher schärfste erlassene Abwehrgesetz dar (S. 128). An der gemeinschaftlichen Regelungskompetenz bestehe spätestens seit Inkrafttreten des Amsterdam-Vertrags kein Zweifel (S. 135). Auch die clawback-Regelung in Art. 6 sei jedenfalls als Repressalie zulässig (S. 137). Bis hierher benötigt Kayser für Beschreibung und Bewertung gut 15 Seiten; fast 60 weitere hingegen widmet er dann zivilprozessualen Regelungen der Verordnung, insbesondere der ,exorbitanten“ Gerichtsstandsvorschrift in Art. 6 Abs. 3! Nach ebenso gewundenen wie eingehenden Erwägungen schätzt Kayser schließlich die „Abschreckungs- und tatsächlich erzielbare Abwehrwirkung der ,clawback'-Vorschrift ... abgesehen vom rein demonstrativen Effekt bei näherer Betrachtung“ als ,denkbar gering“ (S. 196) ein und überträgt diese Beurteilung auf die Verordnung als Ganze, habe sie doch ,gut drei Jahre nach ihrem Erlaß“ - und bis heute - „noch zu keinerlei Einlenken auf Seiten des US-amerikanischen Gesetzgebers geführt“ (S. 197). Speziell im Hinblick auf den neu eingeführten Vermögensgerichtsstand sei ,der rechtspolitische Sündenfall zu groß, als daß er angesichts der geringen dadurch tatsächlich zu erzielenden Wirkung in Kauf genommen werden sollte“ (S. 199).

Die Zusammenfassung der Ergebnisse in sechs Punkten mündet in den Ratschlag, ein Lösungsansatz solle auch in Zukunft dort gesucht werden, ,,wo die Wurzel extraterritorialer Konflikte liegt: auf der unmittelbaren Ebene des Verhältnisses der Staaten zueinander, also in Außenpolitik und Völkerrecht“; zu erhoffen sei von diesem „,die allgemeine Anerkennung und Fortentwicklung der völkerrechtlichen Konfliktlösungsmechanismen“ (S. 207).

Weniger durch diesen Schluß als durch den zu großspurigen Titel enttäuscht Kayser einige Erwartungen, die nicht zuletzt durch ein eindrucksvolles Literaturverzeichnis geweckt werden. Die völkerrechtlichen Aspekte kommen deutlich zu kurz, countermeasures bilden allenfalls ein Randthema. Hilfreich ist der Abdruck der beiden Rechtsakte im Anhang, minder erfreulich das Fehlen eines Stichwortverzeichnisses. So sehr die systematische Behandlung der internationalen/örtlichen (Gerichts-)Zuständigkeit beeindruckt, so akribisch auch die diversen Sanktionsmaßnahmen aufgelistet werden, so rasch geht Kayser über international- und verfassungsrechtliche Schranken einer ,moralisierten“ Außenpolitik à l'américaine hinweg. Wie der durch Helms-Burton- oder andere Akte betroffene Staat zugunsten ,seiner“ Unternehmen reagieren darf, soll oder gar muß, ergibt sich letztlich aus völkerrechtlichen Grundsätzen (Art. 2 UN-Charta) wie aus vor allem grundrechtlichen Schutzpflichten; daher wäre es gerade angesichts des Kayser'schen Ausblicks naheliegend (gewesen), Parallelen und Unterschiede zur Verordnung Nr. 3286/94/EG, dem 1994 an das 
WTO-Recht angepaßten „Neuen Handelsinstrument“ aufzuzeigen. Immerhin macht Kaysers Arbeit klar, daß auch aus einem ausgefeilten Arsenal zivilrechtlicher Instrumente kein wirklich effektives blocking statute entsteht.

Ludwig Gramlich, Chemnitz

Stefan Brüne (Hrsg.)

\section{Neue Medien und Öffentlichkeiten}

Politik und Tele-Kommunikation in Afrika, Asien und Lateinamerika, 2 Bände

Schriften des Deutschen Übersee-Instituts Hamburg, Bände 46 und 47

Deutsches Übersee-Institut, Hamburg, 2000, 451 S. (Bd. 1), 434 S. (Bd. 2),

je Band DM 58,--, zus. DM 96,--

Das Informationszeitalter ist längst angebrochen. Auch wenn die New Economy nicht mehr boomt, der Einfluss und die Bedeutung des Internets im Hinblick auf gesellschaftliche Veränderungen ist ungebrochen. Gilt diese Erkenntnis unbestritten für die sog. entwickelte Welt der klassischen Industrieländer, ist ein Blick auf den übrigen Teil des Globus Stichwort: globalisierte Kommunikation - besonders interessant. Wie so häufig verengt sich aber der hiesige Blick auf die uns umgebende Lebenswirklichkeit, obwohl gerade das Aufkommen neuer Medien eine ungeheure Dynamik auch in technisch minder ausgestatteten Ländern in Gang setzen kann. Um vernünftig über die Wirkungen neuer Informationsund Kommunikationstechnologien angesichts ihrer weltweiten Verbreitung sprechen zu können, bedarf es eines empirischen Befundes über die Staaten auch und gerade Afrikas, Asiens und Lateinamerikas. Diese Aufgabe hat dankenswerter Weise Herausgeber Brüne mit den beiden Bänden zu Neuen Medien und Öffentlichkeiten übernommen.

Das Sammelwerk vereint mehr als 30 Beiträge zu den Stichworten Medien und Entwicklung, Medien und Demokratisierung, Internet und Politik (Bd. 1), Alternative Medien sowie Telepolitiken und Medienökonomie (Bd. 2) aus politologischer, soziologischer, publizistischer und ethnologischer Sicht. Die enthaltenen Fallstudien eröffnen den Blick auf eine hier weitgehend unbeachtete Medienwelt und erhalten eine systematische Einordnung durch übergreifende Analysen der Auswirkungen neuer Medien auf die sog. Dritte Welt. Zwar ist die Auswahl der besprochenen Staatenbeispiele durchaus etwas zufällig, insbesondere ist nicht der Versuch einer kompletten oder repräsentativen Länderuntersuchung unternommen worden. Nichtsdestoweniger ermöglicht die Zusammenstellung einen interessanten Einblick in die Vielfalt der angesprochenen Themen. Einige der Beiträge sind dabei Neudrucke vergriffener Artikel, allesamt sind sie entstanden im Rahmen der Arbeitsgruppe Internationale Medien und Politische Kommunikation des Deutschen ÜberseeInstituts unter Leitung von Becker, Brüne und Hafez. 
Vielleicht ist das Fazit der Thematik schon das an den Anfang des ersten Beitrags gestellte Zitat: „Technology changes everything and nothing“. Die Gefahr eines digital divide sowohl in der Weltordnung zwischen den reichen und armen Ländern sowie innerhalb der Industriestaaten zwischen höher qualifizierten und weniger gebildeten Bevölkerungsschichten ist eminent und wäre eine Fortführung bestehender Verhältnisse unter neuen medial ausgerichteten - Rahmenbedingungen. Andererseits gibt es doch Veränderungspotentiale und zwar sowohl in negativer Hinsicht, man denke an die Problematik kultureller Einebnung regionaler Besonderheiten durch das anglozentrierte Internet, wie auch in positiver Hinsicht. Das Beispiel China wird mit Sicherheit eines Tages die Richtigkeit des alten Sprichworts zeigen, dass steter Tropfen den Stein höhlt. Zwar wird durch die Einführung des Internet nicht plötzlich eine die Meinungsfreiheit fördernde Atmosphäre in der Volksrepublik geschaffen, aber die Tropfrate und damit das Höhlen des Steins wird erheblich beschleunigt. Schon heute ist zu beobachten, dass der eindringende Informationsfluss und die alternative Unterrichtungsmöglichkeit für die Bürger durch die Nutzung des - wenngleich nur beschränkt zugänglichen - Internet schwerer zu kontrollieren sind als beispielsweise der Inhalt von Presseerzeugnissen. Eine weitere Veränderung ist bei marginalisierten Gruppen festzustellen. Indigene Völker beispielsweise bedienen sich der Möglichkeiten des Internet zur besseren Kommunikation untereinander und erhöhen damit den Grad ihrer Organisiertheit. Aus eigener Erfahrung weiß der Rezensent, wie beispielsweise die Indianer in den USA - zumindest in Teilen - ganz selbstverständlich mit Internet und Email arbeiten. Exemplarisch sollen im Folgenden einzelne Beiträge im Spannungsfeld dieser Optionen beleuchtet werden, um damit einen Eindruck des Sammelwerks zu vermitteln.

Brüne versucht einleitend die „ehemalige Dritte Welt, die Alten und die Neuen Medien“ in Beziehung zueinander zu setzen. Dabei weist er im Sinne einer Einführung auf einige Widersprüche hin, die teilweise in den Folgeartikeln vertieft werden. So gilt Indien zwar als Brutstätte hoch qualifizierter Software-Experten, die Telekommunikations-Infrastruktur des Landes lag dagegen noch vor Jahren fast vollständig brach. So war zum Beispiel 1994 kaum mehr als ein Telefonhauptanschluss auf hundert Einwohner registriert (S. 18). Daher dürfe man Öffentlichkeiten in Ländern des Südens (noch?) nicht mit massenmedialer Öffentlichkeit gleichsetzen, weil gerade dort eine gespaltene Wirklichkeit zwischen städtischen und ruralen Gebieten bestehe (S. 30 f.). Dennoch entspricht der Einstiegsbeitrag nicht ganz den hohen Erwartungen aus dem Titel, weil er zum einen nicht mehr ganz zeitgemäß ist, was natürlich gerade bei dem Tempo der technologischen Entwicklung nicht ganz unproblematisch ist. Zudem bleibt manches unverständlich, wie wenn es auf S. 23 heißt, dass der afrikanische Kontinent „bis zum Jahr 2001 (...) an das Internet angeschlossen" sein soll: in erster Linie wird damit die technische Anbindung an das backbone des Internet, nicht aber die Verfügbarkeit verschiedener Knoten im Landesinneren gemeint sein. Eine Fülle weiterführender Literaturhinweise ermöglicht jedoch ohne weiteres ein vertiefendes Studium. Seibel / Müller-Falcke / Bertolini stellen gleich zu Beginn die These auf, dass die Rolle der Zivilgesellschaft und Popularität lokaler Kulturen durch die Verbreitung neuer Medien gestärkt wird (S. 43). Der Weg dahin ist jedoch lang: so ent- 
spricht die Gesamtsumme aller Telefonanschlüsse in den 48 am wenigsten entwickelten Ländern weniger als einem Prozent der Leitungen in den USA, obwohl dort nicht einmal halb so viele Menschen leben. Die Finanzierung der nötigen Investitionen stellt denn auch ein Haupthindernis dar. So zeigt gerade das auf S. 67 optimistisch angeführte Beispiel des Unternehmens Iridium als Anbieter weltweit nutzbarer Satellitentelefonie auch die Fehlerquote von Prognosen im Telekommunikationsbereich. Nach dem Konkurs von Iridium konnte die temporäre Abschaltung des Dienstes nur durch eine Intervention des amerikanischen Verteidigungsministeriums zusammen mit einem großen Unternehmen aus der Branche rückgängig gemacht werden.

Die Autoren zeigen eine mit den neuen Informations- und Kommunikationstechnologien aufkeimende Chance für Entwicklungsländer, die aber letztlich zu einer Fortsetzung der qualitativen Benachteiligung auf dem globalisierten Arbeitsmarkt führt. Es können nunmehr aufgrund der leichten Übertragbarkeit manuelle Datenerfassungen in Länder mit niedrigem Lohnniveau ausgelagert werden - so beim bekannten Beispiel des ,alternativen“ Telefonbuches - und die Ergebnisse dieser Arbeiten werden per Datenleitung dann an den Auftraggeber zurückgesandt (Seibel / Müller-Falcke / Bertolini, S. 72 f.). Im Ergebnis bleibt damit die kapitalträchtige Vermarktung in den Händen der entwickelten Länder, und es ändert sich lediglich der Inhalt der manuellen Vorarbeit. Es wird nur eine Umstrukturierung erreicht. Andererseits könnte das Internet eine Bildungsoffensive unterstützen, wenn man einen Zugang für eine größtmögliche Zahl von Nutzern herstellt. Solche Modellversuche haben in den USA zur Einrichtung öffentlicher kostenfreier Zugangsmöglichkeiten in Bibliotheken (mittlerweile in 90\% verfügbar) und Community Technology Centers geführt, was aber Investitionen von Regierung, Industrie und gemeinnützigen Stiftungen von bis zu 10 Mrd. \$ bislang erforderte (Baumgartner, NZZ Nr. 112 v. 16.05.2001, S. 10). Dies übertragen auf die Entwicklungsländer zeigt, dass die Entwicklung insgesamt skeptisch zu betrachten ist und das Fazit der Autoren auf S. 86 daher richtig ist, dass lediglich eine Chance besteht, die Entwicklungsländer in das „globale Dorf“ zu integrieren. Dazu wird auch erforderlich sein, dass liberalisierte Märkte reguliert werden und nicht zuletzt eine staatsferne (Regulierungs-)Behörde eingerichtet wird, die mit Berechenbarkeit potente Investoren locken kann. Gerade die Schaffung gesetzlicher Regelungen als Basis für Entwicklung ist für den (Medien-)Juristen von größtem Interesse, während er hier nur am Rande Raum findet. So zeigt sich abermals, wie unterschiedlich die Disziplinen einer Fragestellung nachgehen. Nicht zuletzt deshalb ist es aber unerlässlich, insbesondere für Juristen, dass der Blick über den Tellerrand des eigenen Fachs gehoben wird, um die tatsächlichen und antizipierten Auswirkungen von Recht verstehen zu lernen.

Über ein halbes Jahrhundert Kommunikationspolitik der UNESCO berichtet Breuning auf 15 Seiten und gibt dabei eine gut lesbare Zusammenfassung aller wichtigen Phasen des durch die beiden Blöcke und die blockfreien Staaten provozierten Widerstreits zwischen Informationsfreiheit verstanden als freier Informationsfluss oder im Sinne eines ausgewogenen (und damit überwachten) Austausches zwischen den Staaten. Der Beitrag beschränkt sich dabei auf eine Beschreibung, ohne die Aufeinanderfolge von unterschiedlichen Kom- 
promissformeln in den zwischenstaatlichen Vereinbarungen kritisch zu durchleuchten. Franzke gibt ein Hörfunkfeature wieder, das in spannender Weise auf wenigen Seiten das Dilemma der Auslandskorrespondenten bezogen auf die klassischen Medien darzustellen vermag. Es sind solche Hintergrundinformation aus der täglichen Arbeit, die viele Schwierigkeiten im Umgang der unterschiedlichen Kulturen miteinander verständlicher machen. Es folgt eine hochinteressante Stellungnahme zum Problem der kulturellen Praxis von Medien, wobei Dracklé überzeugend ethnologische Kategorisierungsvorschläge für zukünftige Untersuchungen macht. Dabei fällt auf, dass hier wie in vielen anderen Beiträgen der Fokus auf den klassischen Medien liegt, was aber folgerichtig ist, weil der Begriff „Neue Medien“ im Kontext von Entwicklungsländern auch und gerade die uns altbekannten audiovisuellen Medien umfassen muss. Das ungemein brisante Kapitel „China und Internet“, also das oben erwähnte Dilemma der Machthaber zwischen wirtschaftlicher Öffnung und ideologischer Abschottung, das sich am Beispiel der Einführung der neuen Kommunikationsplattformen besonders plastisch belegen lässt, bleibt in den beiden Beiträgen von Dao-Yuan und Kahls, die in erster Linie beschreibend die bisherigen Entwicklungsschritte nachvollziehen und das Problem mit den chinesischen Schriftzeichen und der Sprache aufzeigen, leider eher an der Oberfläche, wenngleich wichtige Fakten geliefert werden.

In der Studie von Baars finden sich zahlreiche bereits vorher beschriebene Erkenntnisse das liegt in der Natur eines Sammelbandes von Beiträgen aus unterschiedlicher Feder und Zeit - zur Entwicklungschance für Afrika. Gewinnbringend am Beitrag ist daher vor allem die deutliche Stellungnahme, die auch nicht davor zurückschreckt, das Sterben oder Verdrängen „kleiner Sprachen“ (S. 367) zu befürworten, um nicht „Afrika vom Fortschritt auszuschließen“. Keinesfalls aber werde es zu einer „Anpassung des Wertesystems und der Gesellschaft an die amerikanische führen“ (ebd.), wie von Kritikern befürchtet. Richtigerweise erkennt Baars im Hinblick auf seine Einschätzungen, dass sich ,die Erforschung der Nutzen und Risiken des Internets in Afrika im rein spekulativen Raum“ bewegen. Damit ist zugleich Notwendigkeit und Schwierigkeit für eine Publikation der vorliegenden Art angesprochen.

Das spiegelt sich denn auch in Band 2 wider, in dem es zunächst um Alternative Medien geht, wobei auch hier der tatsächlichen Lage entsprechend ein Schwerpunkt auf kleinen Radiosendern liegt. Das letzte Kapitel befasst sich vor allem mit der wirtschaftlichen Bedeutung von Medienunternehmen und -unternehmungen insbesondere in Lateinamerika. Ein weiterhin hochrelevantes und in seiner Brisanz zunehmendes Feld ist die von Hintz analysierte globale Medienkonzentration, die sich zum einen in spektakulären Fusionen wie zwischen AOL und TimeWarner, aber auch unauffällig und unaufhaltsam durch Übernahmen in kleinen Schritten vollzieht. Wie eng Medien- und politische Macht liegt, zeigt am besten vielleicht das Beispiel des jüngsten Wahlgewinns von Berlusconi in Italien. Neben den durch das Internet ausgelösten Konzentrationstendenzen darf die schon lange bestehende, fast monopolartige Situation bei der Informationsverarbeitung durch Nachrichtenagenturen nie vergessen werden. Es ist das Verdienst von Hintz, das auch in dieser Publi- 
kation die geringe Zahl der global players im nachrichtenverarbeitenden Gewerbe aufgezeigt wird. Hier dominieren schon seit eh und je Reuters, Associated Press (AP) und Agence France Presse (AFP) das Korrespondentennetz und bestimmen damit schon durch die Vorauswahl die Schlagzeilen der weltweiten Nachrichten. Dies gilt im Übrigen für die Fernsehbilder genauso und zwar gerade seit Einführung von Nachrichtenkanälen wie n-tv auch in Deutschland. Hintz versteht ,alternative media“ in Form unabhängiger Nachrichtenplattformen im Internet oder lokalen (Piraten-) Radiostationen denn auch als Opposition, nicht Ergänzung zu bestehenden Nachrichtenwegen (S. 27). Indigene Völker, genannt werden die Maori in Neuseeland, behelfen sich durch Aufbau eigener Medien gegen die Vereinnahmung kultureller Eigenheiten im Rahmen des ,global village“ und wehren sich damit auf eigene Art gegen weltweite Konzentrationstendenzen.

In einem seiner Beiträge beleuchtet Kuhl die politischen Untergrundsender in Afrika, wobei er die entscheidende und erschütternde Rolle des ,,hate radio“ („Hassradio“) bei der Einleitung des Genozids 1994 in Ruanda darstellt (S. 109 ff.). Damit lenkt er die Aufmerksamkeit auf die negativen Aspekte von Medien, die als Propagandainstrument missbraucht werden. Baer ergänzt ebenfalls die Erkenntnisse aus dem ersten Band um praktische Einblicke in den versuchten Aufbau regionaler Tauschsysteme für Fernsehbilder, um die fast schon paradoxe Abhängigkeit afrikanischer Fernsehsender von Bildern europäischer Fernsehstationen für die Darstellung afrikanischer Ereignisse zu mindern. Den Blick nach Südamerika lenken Kunczik und Zipfel. Gemeinsam beschäftigen sie sich ausführlich mit dem brasilianischen Fernsehunternehmen Globo und dem mexikanischen Gegenstück Televisa. Beide „Mediengiganten“ sind auch am Weltmaßstab gemessen sehr erfolgreich und gehören mit den eigenproduzierten sog. Telenovelas zu den Hauptexporteuren dieser Länder. Hier ist einer der wenigen Beispiele, zudem auf der Unterhaltungsebene, eines Austausches von Süd nach Nord, im Gegensatz zur allgemeinen Einflussrichtung.

Abgerundet wird das Sammelwerk durch eine 65-seitige Bibliographie, die nicht zuletzt den hohen Nutzen für Wissenschaftler aus dem angesprochenen Leserkreis erklärt. Aber auch für andere an der Wirkung von Medien Interessierte sind die beiden von Brüne herausgegebenen Bände ein gelungener Griff, wobei die einzelnen überwiegend in deutsch, teilweise in englisch gehaltenen Beiträge sowohl als Gesamteinblick, aber auch zum jeweiligen Sachgebiet herangezogen werden können. Etwas problematisch ist das Alter des Zahlenmaterials in vielen Beiträgen, da von einer schnellen Änderung gerade bei der Verbreitung des Internet ausgegangen werden kann. Insoweit sind Zahlen aus Studien von 1995 heute schon Geschichte. Andererseits stellt es ein großes Problem dar, aktuelleres aussagekräftiges Zahlenmaterial im Hinblick auf die besprochenen Staaten zu erhalten, das nicht vage Vermutung ist. Daher sind die als „Reader konzipierten Sammelbände“ (Vorwort, S. 11) als ein ,work in progress“ zu verstehen und bieten einen interessanten Werkstattzwischenbericht zu Beginn des neuen Jahrtausends. Die Erkenntnisse sollten Anlass sein, Forschungen auch im Hinblick auf weitere Staaten anzugehen, weil zum Beispiel das nur am Rande (im Hinblick auf Satellitenfernsehen) erwähnte Indien wegen seiner bekanntermaßen erfolgreichen Ausbildung von Informationstechnologie-Experten im Hinblick auf 
die im Land selbst verbreitete Nutzung des Internet ein aufschlussreiches Feld sein dürfte. Abschließend sei zu den Bänden vermerkt, dass sie in der Schriftenreihe des renommierten Deutschen Übersee-Instituts in Hamburg verlegt werden, aber die Buchbindung dieser Reihe bedauerlicherweise in Einzelfällen häufigem Blättern nicht standhält.

Das Bild des weit verbreiteten, per Satellitenmobilfunk mit dem Internet verbundenen Laptop am Lagerfeuer in der Savanne Afrikas, der Wüste Indiens oder den Bergen Südamerikas dürfte romantische Vision der Technikgläubigen bleiben. Dennoch sollten im Sinne einer Bildungsoffensive die Möglichkeiten des Internet weltweit mehr Menschen zugänglich gemacht werden. Diese, negativ ausgedrückt, missionarische, positiv dagegen als entwicklungsfördernd und -fordernd zu bezeichnende Haltung, lässt sich bei den meisten Autoren des Werkes „Neue Medien und Öffentlichkeiten“ herauslesen. Zu Recht nehmen sie damit eine - zustimmungswürdige - Wertung vor, ohne die man sich diesem Themenfeld nicht nähern kann.

Mark D. Cole, Mainz

Max-Planck-Institut für ausländisches und internationales Privatrecht (Hrsg.)

\section{Rechtsquellen des MERCOSUR}

Teilband II: Handel und Verkehr; spanischer Text und deutsche Übersetzung Nomos Verlag, Baden-Baden, 2000, 440 S., DM 118,--

Trotz einiger Krisen in den vergangenen Jahren kann der Mercosur nach wie vor als einer der wichtigsten und auch erfolgreichsten wirtschaftlichen Zusammenschlüsse bewertet werden. Allein sein Handelsvolumen als viertgrößter Block in der Welt und die sich ausweitende und verdichtende Kooperation mit der Europäischen Gemeinschaft veranlassen zu einer Beschäftigung mit den Prozessen im südlichen Lateinamerika. Hilfestellung sowohl für die akademische als auch die praktische Arbeit bietet dabei der Teilband II der Rechtsquellen des MERCOSUR - wie dies auch schon für Teilband I (vgl. die Rez. in VRÜ 33 (2000), Heft 2, S. 263 f.) galt.

Nachdem Teilband I in umfangreicher Weise Normativakte im Bereich der institutionellen Grundlagen, der regionalen und internationalen Beziehungen, des Wettbewerbsrechts, der Rechtsverfolgung und des Verbraucher- und Umweltrechts in der authentischen spanischen Fassung und in deutscher Übersetzung zur Verfügung stellte, beschäftigt sich nun Teilband II im wesentlichen mit den Gebieten Handel und Verkehr.

Der umfangreiche Abschnitt über den Warenverkehr enthält neben dem rahmengebenden Freihandelsplan die ,sekundärrechtlichen“ Vorschriften über den Abbau der Binnenzölle, den der nicht-tarifären Handelshemmnisse, über den gemeinsamen Außenzoll sowie über die für den Freihandel wichtigen Ursprungsregeln. Der sich mit dem Dienstleistungsver- 
kehr beschäftigende Teil umfaßt Regelungen zur Liberalisierung des Dienstleistungsverkehrs sowie zum Versicherungsmarkt, während der Abschnitt über Transport und Verkehr alle relevanten Normen im Bereich der physischen Infrastruktur, die ja gerade für die praktische Umsetzung des Freihandels von Bedeutung ist, aufweist. Daran schließen sich die Regelungen über den Kapitalverkehr an, u.a. sind die relevanten Normen des Investitionsschutzes abgedruckt, die vor allem für Unternehmen auch außerhalb der Region wesentliche Bedeutung haben dürften. Der letzte Teil beinhaltet Normativakte zum Personenverkehr, die sich von Regelungen über Reisedokumente über die Anerkennung von Abschlüssen bis zur Sozialversicherung erstrecken.

Beachtenswert ist bei der Zusammenstellung schon allein der Umfang der Rechtsnormen, die bisweilen sehr schwer anderweitig aufzufinden sind. Nützlich ist auch, daß sich bei vielen Rechtsakten in Fußnoten Verweise auf andere relevante, zu beachtende Normen finden, was das Arbeiten mit der Fülle der Entscheidungen und Resolutionen der jeweiligen Mercosur-Organe erleichtert. Ein chronologisch aufgebautes Register am Ende des Bandes hilft bei der Einordnung des geltenden Rechts.

Bedauernswert, wenn auch konsequent, ist, daß sich wie in Teilband I keine Erläuterungen etwa zur Form der Rechtsakte finden. Der Benutzer der Rechtsquellen braucht daher schon einige Vorkenntnisse, um eine Einordnung vorzunehmen. Der Laie könnte etwa bei Titeln von Rechtsakten wie dem „Programm der Handelsliberalisierung“ oder etwa einem „Arbeitsdokument“" zum Freien Kapitalverkehr an deren rechtlicher Verbindlichkeit zweifeln. Leider findet sich auch das nicht vollständige Abkürzungsverzeichnis etwas versteckt am Beginn des Registers.

Trotzdem ist auch der zweite Teilband der Rechtsquellen des MERCOSUR schon wegen seiner Einzigartigkeit im deutschsprachigen Raum für alle am Mercosur Interessierten eine sehr nützliche Zusammenstellung.

Julia Lehmann, Berlin

\section{Jennifer Corrin Care / Tess Newton / Don Paterson}

\section{Introduction to South Pacific Law}

Cavendish Publishing, London / Sydney, 1999, 402 pp., £ 20.00

Auf knapp 400 Seiten eine Einführung in „das Recht” von insgesamt elf Staaten (bzw. unabhängigen Gebieten) zu präsentieren, die alle großen Rechtsgebiete berücksichtigt, erscheint auf den ersten Blick als verwegenes Unternehmen. Es gibt wohl auch nicht viele Gegenden dieser Welt, für die man dies als sinnvoll erachten würde. Nun leben in den elf Rechtsordnungen, um die es in dem vorliegenden Buch geht (Cook Islands, Fiji Islands, Kiribati, Nauru, Niue, Samoa, Solomon Islands, Tokelau, Tonga, Tuvalu, Vanuatu) insge- 
samt nicht mehr als etwa 1,7 Millionen Menschen. Diese Staaten und Gebiete betreiben eine gemeinsame Universität (University of the South Pacific, USP) mit Hauptsitz in Suva (Fiji), die seit einigen Jahren über eine juristische Fakultät verfügt, ausgelagert in Port Vila (Vanuatu). An dieser Fakultät (deren Bibliothek kurioserweise mit chinesischer Unterstützung errichtet wurde) wird inzwischen ein beträchtlicher Anteil des Juristennachwuchses der Region ausbildet und dort forschen und lehren die an der Darstellung beteiligten Autoren. Konsequenz der auf den Wirkbereich der USP zugeschnittenen Darstellung ist, dass Papua-Neuguinea, eine Reihe mikronesischer Staaten, die US-amerikanischen Gebiete sowie die französischen Territoires Outre Mer (,TOM“) ausgeklammert bleiben. Für die verbleibenden Rechtsordnungen ergibt sich auch materiell manche Vergleichbarkeit. Homogenität besteht zunächst hinsichtlich des Fundaments im englischen Common Law (einiger französischer Einfluss wirkt lediglich in Vanuatu fort; der in Art. 93 der Verfassung Vanuatus ausdrücklich geregelte englisch-französische Rechtsdualismus findet in der vorliegenden Darstellung allerdings keine nähere Betrachtung). Gemeinsam ist den Rechtsordnungen (mit Ausnahme Tokelaus) auch die von der englischen Tradition abweichende Existenz geschriebener Verfassungen sowie das Bemühen, in gewissem Maße ,traditionales" Recht (customary law) zu bewahren. Insgesamt verbindet die Staaten also genug, um eine integrierend-vergleichende Betrachtung sinnvoll erscheinen zu lassen, zumal jedes Buch zum Gegenstand zunächst einmal insofern einen Fortschritt bedeutet, als die Literaturlage zu den Rechtsordnungen dieser „Mikrostaaten“ naturgemäß bescheiden ist.

Das Buch besteht im Einzelnen aus vier Grundlagenkapiteln über die Typologie südpazifischen Rechts, historische Bezüge und indigene wie importierte Rechtsquellen, dem sich Verfassungs- und Verwaltungsrecht, Strafrecht, Vertragsrecht, Deliktsrecht, Landrecht und Gerichtsverfassungs- sowie Prozessrecht anschließen (Kapitelüberschriften im Original: South Pacific Law and Jurisprudence, Constituent Laws, Local Laws, Received Law, Constitutional Law, Administrative Law, Criminal Law, Contract Law, Torts Law, Land Law, Hierarchy of the Courts, Civil and Criminal Procedure). Angesichts der Literaturgattung (,Einführung“) und der auf knappem Raum zu bewältigenden Themenmasse wenig verwunderlich ist, dass das Buch in weiten Teilen eher darstellend als analytisch ist. Allerdings vermisst man ein wenig die Reflexion über die tatsächliche Funktionsfähigkeit des importierten Rechts in der Region. Nicht erst seit den neuesten Putsch-Szenarien in Fidschi und auf den Solomonen im Jahr 2000 sowie den jüngsten Gewaltausbrüchen in Papua-Neuguinea im Juni 2001 wird hierüber diskutiert. Im Abschnitt über „Jurisprudence“ (S. 5 ff.) finden sich hierzu nur einige knappe Andeutungen. Im Übrigen ist das Werk ein echtes juristisches Lehrbuch in dem Sinne, als es sich auf Normen und Rechtsprechung konzentriert und die hintergründigen Rahmenbedingungen sowie die Lebenswirklichkeit südpazifischen Rechts ausblendet. Immerhin auf der normativen Ebene werden aber durchweg die Besonderheiten akzentuiert, sowohl im Vergleich des südpazifischen Rechts zum britischen Mutterrecht, als auch im Binnenvergleich der USP-Staaten. Instruktiv ist insbesondere das 25-seitige Kapitel über „Customs and Customary Law“ (S. 24 ff.), das sich im Gegensatz zu vielfältigen Abhandlungen zum Thema in erfreulicher Weise nicht in theoretischer 
Reflexion erschöpft, sondern konkrete Gesetzgebung und Rechtsprechung auswertet. Auch das Kapitel zum Landrecht (S. 231 ff.) ist geprägt durch die regionalen Besonderheiten; hier finden sich auch einige Hinweise zu anthropologischen Hintergründen. Für den deutschen (bzw. allgemein den nicht-südpazifischen) Leser weniger spannend sind naturgemäß die Passagen zu Rechtsgebieten, in denen sich keine grundsätzlichen ,indigenen“ Besonderheiten feststellen lassen. Auch hier liefert die Darstellung aber vielfältig regionale Gesetzgebung und Rechtsprechung; sie ergänzt insofern für den primären Leserkreis Studenten und Juristen aus der Region - die allgemeine (insb. englische, australische und neuseeländische) Fachliteratur.

Die Darstellung von Care / Newton / Paterson stellt mit ihrem systematisch-länderübergreifenden Ansatz eine gute Ergänzung zu dem von Michael A. Ntumy herausgegebenen Band (South Pacific Islands Legal Systems, Honolulu 1993) dar, in dem bei etwas breiterem territorialen Ansatz Einzelberichte über die Rechtssysteme der Staaten und autonomen Gebiete des Südpazifiks versammelt sind. Auf dieses - inzwischen leider nicht mehr ganz aktuelle - Buch von Ntumy muss nach wie vor zurückgreifen, wer sich über vorhandene Literatur orientieren will. Damit ist der vielleicht wichtigste Kritikpunkt an dem hier angezeigten Werk angesprochen. Es fehlen eine gesamt- oder kapitelbezogene Zusammenstellung von Literatur und ein echter research guide. Die Nachweise in den Fußnoten konzentrieren sich auf Gesetze und Judikatur, Literatur wird nur sehr sporadisch angeführt. Gerade weil Literatur über südpazifisches Recht spärlich und schlecht dokumentiert ist, wäre es aber umso wichtiger, wenn sich eine Einführung der vorliegenden Art, die selbst in allen Themenbereichen nur sporadisch sein kann, auch um weiterführende Hinweise bemühen würde. Wünschenswert wäre, wenn eine Neuauflage hier nachbessern würde. Zur Ergänzung sei an dieser Stelle aber auf die Homepage der Rechtsfakultät der USP verwiesen (http://www.vanuatu.usp.ac.fj/), auf der sich nicht nur ein Online-Law Journal (mit Rezensionsteil), sondern auch eine im zügigen Aufbau befindliche Sammlung mit „Pacific Law Materials“ (Verfassungen, Gesetze, Gerichtsentscheidungen) befindet. Das vorliegende Buch ist nur ein Kondensat der Forschungsarbeit, die an einer einzelnen und nach hiesigen Maßstäben kleinen juristischen Fakultät für die Rechtsordnungen einer ganzen Region erbracht wird.

Jörg Menzel, Bonn 


\section{Frank-Florian Seifert}

\section{Das Selbstbestimmungsrecht der Sri Lanka-Tamilen zwischen Sezession und Integration}

Frank Steiner Verlag, Stuttgart, 2000, 394 S., DM 130,--

Die im Sommer 1999 von der juristischen Fakultät der Universität Leipzig angenommene Dissertation setzt sich zum Ziel, zum einen ,der sich abstrakt mit dem Selbstbestimmungsrecht der Völker auseinandersetzenden völkerrechtlichen Theorie einen konkreten Selbstbestimmungsfall vorzustellen“ (S. 1), zum anderen ,den zahlreichen Studien des Selbstbestimmungsfalles der Sri Lanka-Tamilen verschiedenster nicht-völkerrechtlicher Wissenschaften die völkerrechtliche Sichtweise vorzustellen“ (S. 3). Erklärte Absicht des Autors ist es, mit der Erfüllung dieser beiden Zielvorgaben „eine Lücke“ (S. 3) zu schließen.

Die Untersuchung ist in 5 Teile gegliedert. Sie beginnt mit einer Einführung (S. 1-24), führt über einen 2. Teil: Allgemeine Erwägungen zum Selbstbestimmungsrecht der Völker (S. 25-78) zu einem (vom Umfang her den Hauptanteil der Arbeit bildenden) Abschnitt über Selbstbestimmung durch Sezession (S. 79-255), einem 4. Teil über Selbstbestimmung durch Integration (S. 256-296) und endet mit einer „Zusammenfassung und Ausblick“ (S. 296-301). Ein Dokumentenanhang, ein Darstellungsanhang und ein anscheinend in „modernen“ Monographien unerlässlicher Anhang zu elektronischen Informationsformen, gefolgt von Literatur-, Quellen-, Rechtsprechungs-, Sach- und Personenverzeichnis, wobei überraschenderweise die Literatur- und Quellenverzeichnisse der Internetdokumente separate Erwähnung finden, schließen das Werk ab.

Die Einführung beginnt richtig mit der Beobachtung, dass das Selbstbestimmungsrecht der Völker im Graubereich zwischen Politik und Recht angesiedelt sei. Die danach folgende Feststellung, selbst der rechtliche Charakter des Selbstbestimmungsrechts sei trotz jahrzehntelanger Behandlung durch die Wissenschaft noch nicht geklärt, erscheint voreilig und im Hinblick auf die intensive Diskussion des Selbstbestimmungsgedankens in der völkerrechtlichen Wissenschaft und Praxis ungerecht. Die Auffassung, die völkerrechtliche Theorie habe noch ,nicht einmal eine abstrakte rechtsdogmatisch überzeugende Konstruktion des Selbstbestimmungsrechts“ (S. 2) anzubieten, wird in der Form unangemessen vorgetragen und im Folgenden nicht belegt. Die Lektüre der Einleitung wird durch apodiktisch formulierte Feststellungen erschwert: Eine überblicksartige Darstellung der Entwicklung des tamilischen Konflikts in Sri Lanka mündet übergangslos in eine Beschreibung von Bürgerkriegen als ethnische und damit Identitätskonflikte, gefolgt von einer Unterteilung in „Konfliktgegenstand“, „Konfliktparteien“ usw., ohne dass sich für den Leser erschließt, was mit dieser Klassifikation, die gliederungstechnisch hervorgehoben ist, für den Untersuchungsgegenstand gewonnen ist. Insgesamt gelingt es dem Verfasser mit der Einführung nicht, an den Gegenstand der Abhandlung heranzuführen. Vielmehr geht er sehr voraussetzungsvoll sofort in medias res. Dabei fördern ohne Not verwendete englische Begriffe im Text die Verständlichkeit nicht. So hätte man - um nur einige Beispiele zu nennen - die Ausdrücke ,non-violent methods““, ,violent methods“ (S. 12) und ,ethnic conflict manage- 
ment" (S. 18), da sie keine feststehenden Ausdrücke sind, ohne Bedeutungsverlust übersetzen können.

Die allgemeinen Erwägungen zum Selbstbestimmungsrecht der Völker im nachfolgenden zweiten Teil beginnen mit einer Darstellung der geistesgeschichtlichen Wurzeln der (hier vorsichtig benannten) Selbstbestimmungskonzeption und ihrer Entwicklung bis zum Ausbruch des zweiten Weltkriegs. Für eine Arbeit, deren erklärtes Ziel es ist, auch die Dogmatik des Selbstbestimmungsrechts durch Konfrontation mit tatsächlichen Fällen voranzubringen, kommt die Würdigung des für die Rechtslage Anfang des 20. Jahrhunderts bedeutenden Aaland-Falles erstaunlich kurz (S. 29). Dies mag dem Wunsch geschuldet sein, in die aktuelle Rechtslage vorzustoßen und die „Historie“ entsprechend kurz zu halten. Doch auch die aktuelleren Fälle sind nicht umfangreicher ausgearbeitet. Hinzu tritt Unklarheit über den Ansatz des Verfassers. Mit der Wendung: „unter dem Gesichtspunkt der gewohnheitsrechtlichen Verfestigung der Selbstbestimmung“ sollten im folgenden die wichtigsten Rechtsakte aus der völkerrechtlichen Praxis genannt werden (S. 31), bleibt für den Leser unklar, ob die „gewohnheitsrechtliche Verfestigung der Selbstbestimmung“ (sofern es „die Selbstbestimmung“ gibt) einen hier erstmals formulierten wissenschaftlichen Ansatz des Verfassers bezeichnet, der zudem die zuvor von der Lehre eingeforderte überzeugende dogmatische Absicherung vermissen lässt. Etwas später wird unter Punkt B. „Objekt und Subjekt des Selbstbestimmungsrechts“ (S. 40) die Auffassung wiederholt, das Selbstbestimmungsrecht der Völker sei weder in seinem Inhalt noch seinem Träger rechtlich gesichert. Dieser nicht neuen und in dieser Pauschalität auch falschen Erkenntnis folgt nun der Hinweis, die Frage nach Inhalt und Träger des Selbstbestimmungsrechts könne auch in dieser Arbeit nicht beantwortet werden; ein Diskussionsrahmen für den Fall Sri Lanka werde aber dargestellt. Es ist gut, wenn angesichts der Unmenge der ungelösten Probleme im Zusammenhang mit dem Selbstbestimmungsrecht nicht der Anspruch erhoben wird, die Antwort auf alle Fragen zur Hand zu haben, angesichts des Themas der Arbeit und der ausdrücklich selbst gesetzten Ziele hätte man hier jedoch zumindest den - dogmatisch abgesicherten - Versuch einer Antwort erwartet. Die nachfolgende knappe Darstellung verschiedenster Facetten der wissenschaftlichen Diskussion um das Selbstbestimmungsrecht gibt einen Überblick über den Stand der Meinungen, lässt eine vertiefte Auseinandersetzung jedoch vermissen. Die abschließenden „Schlussfolgerungen“ enthalten keine eigene abstrakte gedankliche Auseinandersetzung, sondern beschränken sich - wie fast alle anderen mit „Schlussfolgerungen“ überschriebenen Untergliederungspunkte auf eine Zusammenfassung.

Nach einer an dieser Stelle etwas unvermittelten Benennung der für Sri Lanka „relevanten“ Aspekte des Selbstbestimmungsrechts, worunter der Verfasser die historische Entwicklung der Sezessionsforderung der Sri Lanka-Tamilen versteht, wendet er sich der Bestimmung des Rechtsträgers des Selbstbestimmungsrechts zu. Auf nur neun Seiten wird die äußerst komplexe Frage der Definition von „Volk“ im Sinne des Selbstbestimmungsrechts abgehandelt und ohne weitere Problematisierung das „Volk“ im ethnischen Sinn als Rechtsträger apostrophiert. 
Im dritten Teil wird die Frage nach der Existenz eines Sezessionsrechtes als Ausdruck des Selbstbestimmungsrechts zunächst durch Überprüfung der Staatenpraxis auf Sezessionsfälle angegangen. Die Darstellung der neueren Ereignisse in Europa (Abspaltung der baltischen Staaten, Zerfall Jugoslawiens und der Tschechoslowakei, Kosovo) ist kursorisch und im Hinblick auf den Zerfall Jugoslawiens zu stark verkürzt; es folgt eine kurze Schilderung der gescheiterten Sezessionsversuche Biafras und Katangas, der „erfolgreichen Sezession“ Eritreas sowie der (wohl noch andauernden) Sezessionsversuche Tschetscheniens, der Fall Ost-Timor und Bangladesh. Eine Studie über die Behandlung der Tamilen-Frage in UNOrganen schließt den Abschnitt ab. Die nachfolgende Diskussion der Voraussetzungen eines Sezessionsrechts in der völkerrechtlichen Theorie (ab S. 122) führt einen Katalog von Sezessionsvoraussetzungen ein (S. 142), dessen Herleitung im Dunklen bleibt, der aber anschließend auf den Fall Sri Lanka angewendet wird. Nach einer umfangreichen Prüfung, dass die Sri Lanka-Tamilen den zuvor aufgestellten Volksbegriff erfüllen (S. 176), tritt die Arbeit in die Untersuchung der Sezessionsgründe ein. Im Anschluss an eine erfreulich tiefgehende Darstellung der verschiedenen Fährnisse und Menschenrechtsverletzungen, denen die Tamilen in Sri Lanka über die Jahrzehnte unterworfen wurden, kommt der Verfasser schließlich zu dem Ergebnis (S. 238), dass sich keinerlei Hinweise auf eine Politik der Vernichtung der ethnischen Gemeinschaft der Tamilen durch die regierenden Kräfte in Sri Lanka fänden und auch eine Gesamtschau der festgestellten Verletzungen nicht ausreiche, ein Sezessionsrecht zu begründen. Insbesondere für letztere Feststellung hätte man gerne eine Begründung gelesen, da das Ergebnis in seiner Eindeutigkeit angesichts der vorher dokumentierten Diskriminierungen doch etwas überrascht.

Der vierte Teil widmet sich in der Selbstbestimmung „,durch Integration“, eine äußerst unglückliche Formulierung, die ein inneres Selbstbestimmungsrecht (also kein ,internes“ Selbstbestimmungsrecht, wie es im Rahmen der Autonomiefrage von anderen Stimmen diskutiert wird) beschreiben soll; selbiges wird ohne zwingende Argumente auf drei Seiten schnell verneint. Es folgt (S. 259 ff.) eine durchaus interessante Auflistung der verschiedenen Vorschläge der Regierungen Sri Lankas zu verfassungsrechtlichen Lösungsversuchen im Umgang mit der Tamilenfrage, die mit einer „Bewertung“ abgeschlossen wird (S. 295), in der sich der Satz findet, eine Bewertung der Vorschläge für eine neue Verfassung sei „unter den gegebenen Umständen nicht sinnvoll“.

Die deutsche und englische Zusammenfassung im 5. Teil ist kurz gehalten, der „Ausblick“ auf S. 301 eigentlich ein Fazit: „Das Völkerrecht kann unter den gegenwärtigen Umständen keinen Beitrag zur Beilegung des singhalesisch-sri-lanka-tamilischen Konflikts leisten und wird dazu auf absehbare Zeit nicht in der Lage sein." Ob dies wirklich so ist, vermag die Rezensentin zumindest nach der Lektüre der vorliegenden Arbeit nicht abschließend zu entscheiden. Auch dieses Buch vermag die darin diagnostizierte Lücke im völkerrechtlichen Schrifttum zum Selbstbestimmungsrecht der Völker nicht zu schließen, es leistet mit der zeitgeschichtlichen Aufarbeitung der Tamilen-Problematik jedoch einen aktuellen Beitrag zur Südasienforschung.

Christiane Simmler, Berlin 


\section{Mathias Rohe}

\section{Der Islam - Alltagskonflikte und Lösungen}

Rechtliche Perspektiven

Verlag Herder, Freiburg i.Br., 2001, 221 S., DM 19,90

Dieses Buch verdient besondere Aufmerksamkeit. Bereits die behandelte Thematik ist von herausgehobenem Interesse, und zwar wegen der wachsenden Bedeutung des Islam in Europa und aufgrund der Emotionen, mit denen einzelne Fragestellungen dieser Thematik in der Öffentlichkeit diskutiert werden. Sodann zeichnet sich das Werk dadurch aus, dass sich der Autor als Jurist und Islamkundler auf der Grundlage wissenschaftlicher Prägnanz in allgemeinverständlicher Sprache der Thematik im jeweils gebotenen Umfang widmet. Damit ist das Buch nicht nur für Fachleute von Gewinn, sondern auch für interessierte Laien bestens geeignet. Es vermeidet viele der üblichen missverständlichen Begriffe und räumt auch mit zahlreichen Klischees und Vorurteilen auf.

Das grundlegende Kapitel über den Islam und die Entwicklung der Scharia beginnt mit einer Einführung in den Islam und in die Scharia, die sich als eine gelungene Gradwanderung zwischen der gebotenen Kürze und fachlicher Genauigkeit darstellt. Zu Recht betont der Autor die Flexibilität der Scharia sowie die bis heute vorhandenen vielfältigen Erscheinungsformen des islamischen Rechts. Den Reformprozess seit dem 19. Jahrhundert interpretiert er zumindest teilweise auch als eine islamkonforme Fortentwicklung des islamischen Rechts. Der Autor gibt einen gelungenen Überblick über die wichtigsten reformerischen Ansätze, wobei er sich kritisch mit den Bewegungen zur Re-Islamisierung auseinandersetzt. Das Kapitel schließt mit der Erörterung wichtiger Reizthemen: der Körperstrafen des koranischen Strafrechts (hudud), des meist fälschlicherweise mit „Heiliger Krieg“ übersetzten dschihad, des Gebotes der Tötung von Apostaten und der Rechtsstellung der Frau. Nach einer historisch/traditionell-rechtlichen Einordnung der jeweiligen Thematik stellt der Autor insbesondere dar, wie die Rechtsinstitute in islamkonformer Weise mit den Erfordernissen einer modernen Gesellschaft in Einklang gebracht werden können.

In den beiden folgenden Kapiteln werden zunächst das notwendige Zahlenmaterial über die Muslime in Deutschland und Europa sowie ihre Zusammensetzung nach Herkunft und Glaubensrichtung innerhalb des Islam vermittelt. Sodann werden die möglichen Formen rechtlicher Koexistenz der vor allem einheimischen nicht-muslimischen Bevölkerung mit der zumeist zugewanderten muslimischen Bevölkerung leicht verständlich dargestellt und in der gebotenen Kürze treffend bewertet. Aufgrund der in Europa geltenden Grundsätze der Einheitlichkeit der Rechtsordnung und der verfassungsmäßigen Religionsfreiheit sei für Europa ein „Mischsystem aus Assimilationsforderung und Akkulturation“ maßgeblich. Nach ausführlicher Auseinandersetzung mit der Religionsfreiheit, deren Schutzbereich und Schranken in Bezug auf die Ausübung der islamischen Religion vor allem in Deutschland geht der Autor der zentralen Frage nach der Vereinbarkeit von Islam und freiheitlich demokratischer Grundordnung nach. Dabei zeigt er auf, dass sich - entgegen der Minderansicht muslimischer Extremisten - der Islam nicht zwangsläufig in einem Gegensatz zu unserer 
Verfassungs- und Rechtsordnung befindet. Vielmehr läßt sich unter Anknüpfung an traditionelle islam-rechtliche Lehren die Bindung des in einem nicht-muslimischen Staat lebenden Muslim an die dortige Rechtsordnung herleiten, wenn nur in dieser die Ausübung der islamischen Religion gewährleistet ist.

In einem separaten Kapitel widmet sich der Autor ausführlich Rechtsfragen des Bürgerlichen wie des Öffentlichen Rechts einschließlich des Strafrechts, soweit diese Bezüge zum Islam aufweisen. Hinsichtlich des Bürgerlichen Rechts behandelt er wirtschafts-, arbeitssowie vor allem familien- und erbrechtliche Probleme. Im Rahmen des Wirtschaftsrechts erörtert er das riba-Verbot, das zumeist - andere Meinungen außer Acht lassend - mit Zinsverbot übersetzt wird, und das Verbot von Spekulationsgeschäften. Dabei zeigt er moderne Ansichten auf, die jene Verbote mit den Erfordernissen des modernen Wirtschaftsverkehrs in Einklang bringen. Eingehender werden arbeitsrechtliche Fragen behandelt, die sich insbesondere aus der Kollision betrieblicher Bedürfnisse mit religiösen Geboten des Islam ergeben wie beispielsweise den Gebetsvorschriften. Die in diesen Fällen rechtlich erforderliche Abwägung der beiderseitigen Interessen ist - wie der Autor überzeugend darlegt - geeignet, die Probleme einer Lösung zuzuführen.

Besondere Aufmerksamkeit widmet der Autor familien- und erbrechtlichen Fragestellungen. Nach einer allgemein verständlichen Einführung in die kollisionsrechtlich bedingte Relevanz des islamischen Familien- und Erbrechts erörtert er kurz, aber eingängig die Vereinbarkeit problematischer Institute und Regelungen des islamischen Rechts mit dem deutschen ordre public, vor allem solcher, die die Frau benachteiligen. Dabei warnt er zu Recht vor einer grundsätzlichen Ablehnung islam-rechtlicher Vorschriften. Ein Bedürfnis für die vertragliche Gestaltung familienrechtlicher Beziehungen sieht der Autor zum einen vor allem in Ehen zwischen einer europäischen Nicht-Muslimin und einem Muslim aus einem islamischen Land zur Verbesserung der Rechtsstellung der Frau. Dabei erörtert er in angemessener Weise die wichtigsten Regelungsgegenstände eines Ehevertrags vor ihrem islam-rechtlichen wie gesellschaftlichen Hintergrund, insbesondere die Vereinbarung einer Brautgabe und diverser Scheidungsrechte für die Frau. Zum anderen weist der Autor auf das mögliche Interesse europäischer Muslime hin, ihre bürgerlichen Rechtsverhältnisse gemäß islam-rechtlichen Vorschriften zu regeln, beispielsweise eine Brautgabe zu vereinbaren. In der vertraglichen Gestaltung, der außerrechtlichen Konfliktvermeidung und der außergerichtlichen Streitbeilegung mit islam-rechtlichen Bezügen sieht der Autor zutreffend erhebliches Entwicklungspotential in Europa. Abschließend gibt er zu überlegen, ob nicht eine weitere rechtskulturelle Liberalisierung insbesondere durch optionale Einführung der islamischen Form der Eheschließung wie beispielsweise in Spanien erfolgen sollte.

Im Rahmen des öffentlich-rechtlichen Teils werden der Moscheebau und der Gebetsruf, die Mission und der Religionswechsel, Bekleidungssitten und Erziehungswesen, der Religionsunterricht, das Schächten von Tieren und Speisevorschriften, das Bestattungswesen, das Sozial- und Steuerrecht, das Staatsangehörigkeits- und Ausländerrecht sowie das Strafund Ordnungsrecht abgehandelt. Hinsichtlich Moscheebau und Gebetsruf ordnet der Autor die Thematik in die religiös-historischen Zusammenhänge ein. Insbesondere zeigt er auf, 
dass weder die äußere bauliche Form der Moschee noch der Gebetsruf religiös zwingend sind. Weiter ordnet er die Problematik in allgemein verständlicher Weise in den bauplanungsrechtlichen und immissionsschutzrechtlichen Zusammenhang ein. Dabei hält er es für denkbar, dass mit zunehmender Gleichstellung der Muslime die Moschee zu einem „,normalen" Bestandteil des Stadtbildes wird.

Ausführlich widmet sich der Autor den mit Bekleidung und Erziehung verbundenen Problemen. Zunächst zeigt der Autor auf, dass sich dem Koran eine bestimmte „Kleiderordnung“, insbesondere das Kopftuch für Frauen, nicht zwingend entnehmen läßt und jenes in der islamischen Welt zwar weit verbreitet, aber zu keiner Zeit unumstritten gewesen ist. Vor diesem Hintergrund erörtert der Autor dann einzelne Rechtsfragen, insbesondere das Tragen von Kopftüchern in Schulen, das ,zur Provokation bzw. zur unzulässigen Demonstration des Glaubens stilisiert" werde. Nach kurzer Auseinandersetzung insbesondere mit der deutschen Rechtsprechung sieht er zu Recht grundsätzlich keine überzeugenden Argumente für ein Kopftuchverbot an deutschen Schulen. Anschließend setzt er sich mit religiösen Vorbehalten vor allem gegen den koedukativen Sportunterricht und den Sexualkundeunterricht auseinander.

Die Einführung eines islamischen Religionsunterrichts an deutschen Schulen ist zu einem zentralen Thema in der öffentlichen Diskussion geworden. Soweit bisher ein derartiger Unterricht durchgeführt wurde, ist dieser zumeist in unzulänglicher Weise auf die wachsende Zahl der hier geborenen und dauerhaft in Deutschland ansässigen Muslime zugeschnitten. Der Autor steckt in allgemein verständlicher Weise den rechtlichen Rahmen für einen islamischen Religionsunterricht ab, dessen Hauptproblem er zutreffend im Bestehen eines für die Inhalte des Lehrplans und die Auswahl der Lehrkräfte verantwortlichen islamischen „Ansprechpartners“ sieht. Denn dafür geeignete hinreichend institutionalisierte und repräsentative islamische Religionsgemeinschaften sind nach Auffassung des Autors bisher nur teilweise vorhanden. Aufgrund dessen und dem Mangel an hinreichend qualifizierten Lehrern dürfte sich ein islamischer Religionsunterricht auf absehbare Zeit nur auf lokaler Ebene realisieren lassen.

Hinsichtlich des islam-rechtlich vorgeschriebenen Schächtens zeigt der Autor auf, wie dieses mit der in Europa üblichen Schlachtmethode in Einklang gebracht werden kann. Folgt man dieser Auslegung nicht, hält der Autor zu Recht einen Anspruch auf eine Ausnahmegenehmigung nach dem Tierschutzgesetz für das Schächten nach islam-rechtlicher Methode auch über das Schlachten zum Opferfest hinaus für gegeben. Auch lassen sich die islamischen Bestattungsriten mit dem hiesigen Bestattungswesen, insbesondere dem Gebot unbefristeter Totenruhe, harmonisieren, wie bestehende Konsenslösungen in vielen Städten zeigen. In Bezug auf das Sozialrecht erörtert der Autor anschaulich, inwieweit religiös motiviertes Verhalten die Hilfsbedürftigkeit herbeiführen kann, sich der Anspruch auf Sozialhilfe auch auf die Kosten für islamische Riten erstrecken kann oder islam-rechtliche Sachverhalte anderweitig relevant werden können. Was das Staatsangehörigkeits- und das Ausländerrecht angeht, so geht er auf religiös bedingte Besonderheiten bei Erwerb der deutschen Staatsangehörigkeit sowie bei Einreise, Aufenthalt und Ausweisung von Musli- 
men ein. Hinsichtlich des Straf- und Ordnungswidrigkeitenrechts betont der Autor zu Recht die strikte Geltung des Strafrechts auch für Muslime und die Bedeutung des staatlichen Gewaltmonopols. Religiös motivierte Verhaltensweisen können allerdings in Einzelfällen gerechtfertigt sein.

In einem abschließenden Kapitel kommt der Autor auf die Perspektiven der Muslime in Deutschland und Europa zu sprechen. Er skizziert die zunehmende Selbstorganisation der Muslime und deren wachsende Teilhabe am öffentlichen Leben, zeigt die Probleme einer Organisation mit staatlicher Mitwirkung auf und geht auf die erstrebenswerte Organisationsform der öffentlich-rechtlichen Körperschaft ein. Auf der Grundlage der für Muslime im Privatrecht bestehenden Gestaltungsmöglichkeiten sieht er zu Recht Ansätze für die Entstehung eines deutschen islamischen Rechts und spricht sich - rechtspolitisch begrüßenswert - für die Einführung wählbarer ,,islam-rechtlich inspirierter Vorschriften“ und der Schaffung einer Institution für Beratung und Mediation von Fällen mit islam-rechtlichen Bezügen aus. Darüber hinaus betont er die Notwendigkeit eines offenen Diskurses zwischen Muslimen und Nichtmuslimen, wobei er es allerdings zu Recht für unverzichtbar hält, Extremisten mit der notwendigen Intensität zu bekämpfen.

Peter Scholz, Berlin

\section{Girma Ghebresillasie}

\section{Kalter Krieg am Horn von Afrika}

Regional-Konflikte: Äthiopien und Somalia im Spannungsfeld der Supermächte 1945-1991

Nomos Universitätsschriften - Politik, Band 33

Nomos Verlag, Baden-Baden, 1999, 280 S., DM 89,--

Nicht eine Gesamtgeschichte der Region hat der Autor verfaßt, sondern ihre gegensätzliche Entwicklung im Rahmen des Interessenkonflikts der USA und der ehemaligen Sowjetunion dargestellt. Zentrales Thema ist die Äthiopienpolitik der USA und der UdSSR, im Spannungsfeld zwischen Äthiopien und Somalia, besonderes deren Rivalität um den Ogaden.

Ghebresellasie will in mehrfacher Hinsicht eine Lücke schließen: Er will zeigen, ,daß das Horn von Afrika, trotz Unterentwicklung und auch ohne im Interessengeflecht der Supermächte zu stehen, eine gewisse Rolle in internationalen Beziehungen spielt.“ (S. 8) Das Interesse des Autors konzentriert sich auf Kontinuität und Wechsel in der Außenpolitik der Supermächte und den Rüstungswettlauf, der geprägt war durch die zweckgerichtete Einflußnahme der USA und der UdSSR. Im Detail erklärt er die Rollen der einzelnen Akteure in der Gestaltung der Außenpolitik dieser Mächte, wobei die der Vereinigten Staaten widersprüchlich und immer neu auf verschiedenen Entscheidungsebenen, die der ehemaligen Sowjetunion immer zentral geführt wurde. 
Nach dem historischen Abriß über die Staaten am Horn und die sehr ausführlichen Analysen der US- und der UdSSR-Außenpolitik schließt sich ein Exkurs zum Thema Djibuti und dessen Bedeutung nach seiner Unabhängigkeit an, sowie Gedanken zu Äthiopien und Somalia in der Zeit nach dem Ende des Kalten Krieges, wobei auch humanitäre Einsätze und militärische Interventionen Berücksichtigung finden.

Ein ungewöhnlich gutes Buch eines außergewöhnlichen Autors. Vielleicht sind es das persönliche Interesse und ein tiefes Verständnis für die gesamte Region, die den Urenkel Kaiser Menelik II. und Enkel Kaiser Iyassu V. von Äthiopien veranlassen, die komplexen Stränge der Politik am Horn von Afrika nach 1945 zu entwirren, sie uns näherzubringen und verständlicher zu machen und dabei völlig neutral zu bleiben. Möglicherweise beruht ein Teil der Erkenntnisse dieses Buches auch auf seiner umfassenden Ausbildung: Sieben Fächer an fünf Universitäten in drei Ländern studiert zu haben, in zwei Fremdsprachen, ist mehr als bemerkenswert.

Das Buch ist eingängig formuliert, fast mitreißend zu lesen. Alles aus einem Guß, voll interessanter Fakten, von denen viele fremd sind, es aber dank des guten gedanklichen Aufbaus und des hervorragenden sprachlichen Niveaus nicht bleiben, und das in einem Fachgebiet, das sonst nur sehr wenige hochspezialisierte Experten bearbeiten.

Bemerkenswert ist über die fünf Kapitel hinaus auch das Nachwort und der Ausblick auf die Zukunft. Diese Abschnitte lesen sich fast wie ein Regierungsprogramm und enthalten sinnvolle, praktikable Vorschläge für die Gesamtregion, wobei Ghebresillasie manche Ideen sicher auch vielen seiner Interviews verdankt, deren Gesprächspartner er aus Sicherheits- und Geheimhaltungsgründen nicht angeben kann.

Wer sich noch detaillierter informieren will, für den zeigen Karten der Länder einen anschaulichen Weg, gegen chronologische Tabellen einen historischen Überblick im Kurzformat und hält die ausführliche Bibliographie noch weitere Wegweiser auch auf Regierungspresse, Dokumente verschiedener Behörden, Redetexte u.ä. bereit.

Zweifellos hat der Verfasser sein Thema kompetent und fundiert bearbeitet, und es ist zu hoffen, daß diese Region Afrikas durch seine Arbeit neue ,Beobachter' findet. Politik und Geschichte als praktisch angewandte Wissenschaften: sehr eindrucksvoll!

Dagmar Reimmann, Tong Norton, GB 


\section{Hüseyin Bagci / Jackson Janes / Ludger Kühnhardt (eds.)}

\section{Parameters of Partnership: The U.S. - Turkey - Europe}

Schriften des Zentrums für Europäische Integrationsforschung / Center for European Integration Studies

Nomos Verlag, Baden-Baden, 1999, 248 S., DM 85,--

„Much could be achieved between Turkey, the European Union and the United States if governments would keep in mind the practical possibilities and the emotional allergies of the partner, and if everybody concerned, the media included, would try to avoid unnecessary damage, try to watch their language, to spare the partner's feelings and to respect his pride and identity.“ (p. 18)

With Turkey at the crossroads of new geopolitical and geoeconomic challenges the strategic dimensions of the triangle U.S. - Turkey - Europe (especially Germany) are highly relevant. This essay collection, published under the auspices of the Center for European Integration at Bonn University in collaboration with the American Institute for Contemporary German Studies in Washington, D.C. and the Middle East Technical University in Ankara, represents the results of long term assessment of all parameters of the partnership.

Divides into four main sections, 1) The Relations between Turkey and the European Union - Stock Taking and Prospects, 2) The Situation of Turks in Germany, 3) Turkey and its Surroundings, 4) Components of a Future Strategy, the work deals with various facets of past and present facts and chances for the future.

In section one Ekkehard Eickhoff analyses the evolution of the relationship between Turkey and Europe from a German perspective while in his paper Haluk Kabaalioglu offers the Turkish view. His is a most detailed historic stock-taking with an examination of the 1963 Association Agreement and a comparison with the Treaty of Rome, the Customs Union with many financial details and the Luxembourg European Council Summit Meeting as well as the Cardiff Council. This author focuses on the Greek Cypriot application for membership in the European Union and points out the problems and impossibilities concerning this most controversial of issues. Günter Joetze's work is called 'The Relations between Turkey and the European Union - A European Perspective'. It consists of 12 strong precise points and calls for the conduct of a critical dialogue with Greece, because "in the long run 'muddling through' is not an adequate method for an area where Europe borders the Greater Middle East with its permanent instabilities" (p. 77). Yakup Atila Eralp also deals with the aftermath of the Luxembourg Summit - Turkey was disappointed by not being made an accession member - and the prospects for a working relationship. Turkish-German relations after 1977, an analysis from a Turkish domestic and foreign point of view is Hüseyin Bagci's contribution. In his estimation the Turkish side is ready for a new beginning now and he believes that it is time for Germany to act, even one-sidedly.

Part two is about the situation of Turks in Germany. Azade Seyhan's essay scrutinizes cultural legacy, legitimacy, and identity in the Turkish Community of Germany, Cem $\ddot{O} z$ demir's a very personal picture of a second generation Turk in Germany. His message to 
all immigrants is to take advantage of their chance to become German citizen so 'they can be counted'. The dialogue between Christians and Muslims in Germany is Barbara HuberRudolf's topic.

The third part of the collection begins with Michael Lake's Report on the Political, Economic, and Social Climate. He is one of the few authors who touches the subject of human rights and Kurdish Turks, the problems with the Greek Cypriot Republic of Cyprus in a larger scale as well as the relationship to Israel. Graham E. Fuller then addresses the sensitive subject of the EU and Turkey's Eurasian Foreign Policy. From an insight into the Turkish internal crisis and international isolation he analysis Turkey's new foreign policy in small case studies with Iraq, Iran, Syria, Egypt and Saudi Arabia, Afghanistan, China and Russia. He concludes that indeed Turkey can and will pursue its own goals but can be a valuable partner to the west. Another unusually personal and unscientific essay is contributed by Ishak Alaton. He focuses on economic and sociocultural developments in his country, paying attention to the problem of inflation, giving examples from towns and regions less well known. Ali L. Karaosmanoglu describes the relationship between Turkey and Russia, emphasizing the importance of the oil business and power politics.

Alan O. Makovsky gives the American perspective of the 'post Luxembourg blues' in the last part dealing with the future relationship. Murat Karayalcin stresses the importance of Turkey in his brief review of the Turkey-Europe Association Relations. He calls Turkey a "fortress in defence of the Western values" and a "vital partner" (p. 214) stating it deserves a place in the Union. One of the editors, the German Ludger Kühnhardt, rounds up the picture. He notes the old ways and new approaches in the triangle, strongly believing there is no alternative to it. "The United States has renewed its commitment as a part and partner of the architecture of European Security, but in the partnership of the United States, Germany and Turkey, it is the Germans and the Turks who must lead." (p. 235)

Apart from a few remarks on German citizenship for Turks that now seem outdated and the fact that there indeed is a fresh approach with the new German administration already, it is a well-researched and interesting volume offering insight into national and transnational law, domestic and international politics, economic factors and is well-balanced thanks to the different national and educational backgrounds of the authors who have contributed to it.

Dagmar Reimmann, Tong Norton, GB 
Ursula Müller / Christiane Scheidemann (Hrsg.)

\section{Gesandt, Geschickt und Abgesandt}

Frauen im Diplomatischen Dienst

Olzog-Verlag, München, 2000, 432 S., DM 68,--

„Frauen sind doch bessere Diplomaten“ war einmal der Titel eines erfolgreichen Ufa-Films. Trotzdem blieb die Diplomatie bis zum Ende des Zweiten Weltkriegs in so gut wie allen Staaten eine reine Männerdomäne und Alexandra Kollontai als sowjetische Botschafterin (seit 1922!) in Mexiko, Norwegen und Schweden eine singuläre Ausnahmeerscheinung. Otto v. Bismarck hätte gar - obwohl selbst verheiratet - einen „Zölibat für Diplomaten“ bevorzugt - wegen der befürchteten Ablenkung vom Beruf durch Familienprobleme. Immerhin aber wurde die Rolle der Ehefrau des Botschafters als Leiterin des mit der Leitung einer Botschaft verbundenen Gästebewirtungsbetriebs dankbar akzeptiert, wenn auch nicht honoriert.

Mit der vom Grundgesetz verbürgten Gleichberechtigung von Mann und Frau wurden beim Neuaufbau des deutschen Auswärtigen Dienstes ab 1950 zunehmend auch Frauen in den höheren Dienst aufgenommen: War es beim ersten Speyerer Attachélehrgang 1950 nur eine - Helene Schöttle geb. Bourbon (1919) -, so ist der Anteil im Jahrzehnt 1990-2000 immerhin auf 82 von 281 gestiegen.

Welche Erfahrungen hat nun das Auswärtige Amt (AA) mit diesen Frauen gemacht, und wie bewerten diese selbst ihren Einsatz in diesem oft mystifizierten, aber auch persiflierten Zweig des öffentlichen Dienstes? Der Beantwortung dieser Fragen nähert sich der hier vorgestellte Band nach einem programmatischen (Müller) und einem historischen (Scheidemann) Einleitungskapitel der beiden Herausgeberinnen im 63 „Berichten und Porträts“, die - oft etwas willkürlich - zu 18 Kapiteln zusammengefasst sind. 48 der Betroffenen kommen selbst zur Wort, 15 werden von der Mitherausgeberin Scheidemann porträtiert. Soweit die Porträtierten noch leben, ist dies schade, denn ihre etwas trocken dargestellten Lebensläufe können es mit den meist ausgesprochen frischen und lebendigen Selbstdarstellungen nicht aufnehmen.

Dies wird besonders deutlich in der Aufeinanderfolge der Präsentation zweier so hervorragender Diplomatinnen wie Renate Finke-Osiander (1926) und Anna-Margareta Peters (1939) im Kapitel „Frauen - Macht - Politik“: Was hätte erstere aus ihrer fast bieder referierten Mitgestaltung der Ostpolitik als politische Referatsleiterin „Osteuropa“ und später Unterabteilungsleiterin darstellerisch machen können! Und wie packend liest sich die Schilderung von Peters über ihre ,prägenden“ Jahre als Protokollchefin des Landes Berlin 1990-1993! Zur Vermeidung späterer Querverweisungen sei auch hier schon auf das persönliche Fazit von Peters hingewiesen, die Frage, ob der diplomatische Dienst eher spezifisch weibliche oder spezifisch männliche Eigenschaften fordere, sei „völlig unwichtig“. Hauptsache sei, dass die Arbeit in „der Sache Sinne“ der bestimmende Kammerton bleibe. Übrigens: Keine der älteren Diplomatinnen hat sich je als Frau diskriminiert gefühlt, 
worauf Mitherausgeberin Scheidemann mehrfach mit fast sichtbarem Kopfschütteln hinweist.

Doch zurück zum Anfang. Von den vier als „erste Frauen im Auswärtigen Dienst“ Vorgestellten gehören eigentlich nur zwei in diese Kategorie: Die in Kairo geborene Rechtsanwältin Margarethe Bitter (1902) und die mütterlicherseits aus einer jüdischen Bankiersfamilie stammende Claire Schild (1919). Weitere bedeutende Vertreterinnen dieser Gruppe, darunter die wegen ihrer Widerstandsvergangenheit besonders eindrucksvollen Hanna Kiep (1904) und Margarethe Lenz-Oevel (1899) finden sich erst vier und sechs Kapitel später unter „Frauen für Frauen“ und „Frauen - Macht - Politik“. Dazwischen findet sich die unvermeidliche „Anstandsdame der Nation“ Erica Pappritz (1893) unter „Protokoll, Kultur und Recht - eine Frauendomäne?““.

Wieso übrigens die traditionell männlich dominierte Juristerei als Frauendomäne?! Hier scheint mir die „Kronzeugin“ Elsa v. Kotzebue (1926) einer optischen Täuschung zu erliegen: Nicht als Frau war sie für eine weniger karriereträchtige konsularische Laufbahn prädestiniert, sondern als Volljuristin. Ich kann mich jedenfalls aus meiner Ausbildungszeit der bewegten Klagen unserer Volljuristen über ihre „ungleichen Startbedingungen“ gut erinnern - weil sie sich nämlich wegen ihrer „,konsularischen Befugnisse“ der Versetzung an einen konsularischen Posten nicht entziehen konnten, während die Nichtjuristen in eleganten Bögen die ,politischen“ Posten ansteuern konnten.

Hier steht dann auch die von mehreren Verfasserinnen aufgestellte Behauptung zur Debatte, dass Frauen im Vergleich zu den ,karrierebewussten“ Männern stärker sachbezogen arbeiteten, also eher an ,interessanten“ als an ,wichtigen“ Posten interessiert seien. Nach meinen eigenen Erfahrungen dürften hier eher individuelle als geschlechtsspezifische Präferenzen vorliegen.

Insistierend fordert jedenfalls Uta König (1960) die Frauen auf, ihre höher zu steckenden Berufsziele „offensiv“ zu vertreten. „Pas trop de zèle!“ möchte man ihr mit Altmeister Talleyrand zurufen und auf Uta Mayer-Schalburg (1940) verweisen, die mit ihrem Rezept, gerade nicht „kämpferisch“ aufzutreten, sondern in der Mitte zu balancieren, als Generalkonsulin in Mailand nicht schlecht gefahren ist. Was aber werden beide von Anna Hochreuter (1964) halten, die alle älteren Kolleginnen pauschal als ,überangepasst, männeridentifiziert, brav und Vatertöchter“ abqualifiziert, um dann von einer ,,anderen Außenpolitik“ zu träumen?!

Hier sei ein Hinweis auf das besonders lesenswerte Kapitel „Frauen im Kader des DDRAußenministeriums“ eingefügt, denn dort gab es neben ausgesprochenen Parteikadern wieder Pieck-Tochter und langjährigen Botschafterin in Belgrad Eleonore Staimer (1906) auch Persönlichkeiten, die den aufrechten Gang nicht erst nach der Wende zu lernen brauchten, wie Hannelore Trinks (1929). Bei Eleonora Schmid (1939), die mit 35 Botschafterin wurde, später in Marokko die Hochachtung auch westlicher Kollegen gewann, um schließlich 1990 ,in die Arbeitslosigkeit entlassen“ zu werden, kommen Zweifel an der Entscheidung von Außenminister Genscher auf, keine Angehörigen des DDR-Außenministeriums in den nun gesamtdeutschen Auswärtigen Dienst zu übernehmen. 
Viele der älteren Diplomatinnen haben den beruflichen Erfolg mit dem Verzicht auf Familienleben bezahlt, sei es freiwillig, sei es nach gescheiterter Ehe. Der Preis war hoch, wurde aber akzeptiert, so Eva Lindemann (1924), Eleonore Linsmayer (1934), obwohl doch die Leitung einer Auslandsvertretung eigentlich ein „Zweipersonenberuf“ ist, wie Sabine Vollmar-Libal (1934) feststellt. Besondere Hochachtung aber verdient Johanna König (1939), die nach dem Unfalltod ihres Mannes in den Philippinen als Witwe mit vier Kindern in den Auswärtigen Dienst eintrat und nach vier anderen Auslandsverwendungen nun Botschafterin in Kigali ist. Und dann stellt sie noch fest, sie habe über speziell an eine Frau gestellte Anforderungen ,nie ernsthaft nachdenken müssen“.

Jüngere Kolleginnen aber versuchen zunehmend, „Kinder, Korps, Karriere“ miteinander zu verbinden, wobei, da ein „transportabler Ehemann“ - Birgit Frie (1966) - nicht leicht zu finden ist, die Kollegenehe immer stärker in den Vordergrund rückt. Das AA hat dieser Entwicklung Rechnung getragen - wie überhaupt in vielen Beiträgen von ,wunschgemäßen“ Versetzungen die Rede ist. Dass die Versetzung an benachbarte Vertretungen ihre Tücken haben kann, zeigt Brita Wagener (1954), die an der Botschaft Tel Aviv tätig war, während ihr Mann die Bundesrepublik bei der Palästinenserbehörde in Jericho vertrat. Parallele Versetzungen gab es zunächst nur an große Vertretungen. Dass es auch an kleineren klappen kann, sogar in einem so männlich dominierten Land wie Korea, zeigt Martina Nibbeling-Wrießnig (1958). Neueste Entwicklung sind ,job-sharing“-Programme - halbtags oder im tageweisen Wechsel -, wie sie Katrin aus dem Siepen (1968) und Deike Potzel (1968) vorstellen.

Wie sieht es nun mit der Bewährung aus? „Bisher hat es bestens geklappt“, stellt Annett Günther (1963) frohgemut fest, Absolventin des ersten gesamtdeutschen Attachélehrgangs aus Gera und nun mit Mann und mittlerweile zwei Kindern auf dem zweiten Auslandsposten in Taschkent. Demgegenüber spricht Angelika Viets (1954), Botschaftsrätin in Peking mit ebenfalls zwei Kindern, besorgt von der „Sisyphusaufgabe“ der ,aufwendigen Reparaturen des außerdienstlichen Lebensbereichs“. In der Tat, je höher die dienstliche Verantwortung, um so schwieriger wird die Harmonisierung mit Familienverpflichtungen. Und ein ,gesplitteter“ Botschafterposten muss wohl erst noch erfunden werden.

Insgesamt bieten die kaleidoskopartig sich verändernden Bilder ein Wechselbad der Reaktionen mit durchaus positiver Grundtendenz, solange jedenfalls der Dienst an der Sache die Profilierung von Personen überwiegt - Birgitt Ory (1964). Einige Nachlässigkeiten und Unvollständigkeiten in den Biographien und bei den Bildunterschriften wiegen nicht allzu schwer. Dass allerdings einem Beitrag statt eines Photos eine Karikatur beigegeben ist, in der Bundespräsident Herzog seine persönliche Referentin fragt, ,...wann war doch gleich dieser Termin, an dem wir die Opfer des Nationalsozialismus nicht vergessen wollten?", ist eine Geschmacklosigkeit, die die Herausgeberinnen hätten verhindern müssen.

Hier liegt ein Band vor, der eher zum Blättern einlädt als zum zügigen Lesen. Hierfür wird er nachdrücklich empfohlen.

Karl Leuteritz, Königswinter 
Karl-Günther von Hase / Johannes Marré (Hrsg.)

\section{Ministerialdirigent a.D. Dr. h.c. Edmund F. (Friedemann) Dräcker}

Leben und Werk

Vom Kaiserlichen Vizekonsul zum indischen Guru

Nomos Verlag, Baden-Baden, 2000, 243 S., DM 39,--

Am 1. April 2001 fand in Bonn eine ,phänomenale Objektübergabe“ statt: Die Herausgeber des hier zu besprechenden Bandes übergaben vor etwa 100 geladenen Gästen dem Haus der Geschichte die Original-Aktentasche des ebenso legendären wie fiktiven Dr. Dräcker mit der darin aufgefundenen Landkarte der Antarktis mit genauer Markierung der Eisscholle, auf der Dräcker im Januar 1982 die Bundesflagge gehisst hatte. Ein Bericht über diese Aktion von Walter Henkels in der FAZ vom 1. April 1982 hatte zu harscher Kritik der DDR am „Wiederaufleben des westdeutschen Imperialismus“ (u.a. in der sozialistischen Wochenzeitung für internationale Politik und Wirtschaft „horizont“ vom 1. Juli 1982) geführt.

Dies ist - neben anderen Skurrilitäten - in der dankenswerten Neuauflage der zuerst 1974 als Privatdruck in der fiktiven „Wissenschaftlichen Verlagsanstalt zur Pflege deutschen Sinngutes“ erschienenen Dräcker-Monografie dokumentiert (S. 71 ff.). Diese unterscheidet sich von der Urfassung nicht nur durch ihr handlicheres Format, sondern auch dadurch, dass die chronologische Abfolge der Dokumente zugunsten einer benutzerfreundlichen Gliederung in 9 Sachkapitel - von „Dräcker und die internationale Politik“ über „Dräckers geistige Höhenflüge“ u.a. bis zu „Dräcker im Rampenlicht“ - aufgegeben wurde.

Bei der Würdigung Dräckers sollte man nicht vergessen, dass er, als er 1936 erfunden wurde, gar nicht im Auswärtigen Amt (AA) angesiedelt war, sondern im Reichsfinanzministerium: Der damals bei der Botschaft Rom tätige Legationssekretär Hasso v. Etzdorf verschaffte sich durch dessen Anrufe aus Berlin die Möglichkeit, sich aus langweiligen Morgenbesprechungen zu absentieren... Zur diplomatischen Wunderwaffe des inzwischen neu gegründeten AA avancierte Dräcker erst, nachdem er 1952 unter Mitwirkung des Leiters des Politischen Archivs Johannes Ullrich dort als Ministerialdirigent z.w.V. reaktiviert und schon 1953 aus Altersgründen in den Ruhestand versetzt worden war. Neben dem Erfinder v. Etzdorf machten vor allem die Botschafer Günter Diehl und Hans (Johnny) v. Herwarth Dräcker durch ihre Berichte immer wieder aktenkundig. Der schon erwähnte Kolumnist Walter Henkels in der FAZ und der Abgeordnete Hans Stercken im Auswärtigen Ausschuss des Bundestags sorgten dafür, dass die deutsche Öffentlichkeit hieran gebührenden Anteil nehmen konnte. Dräckers Aktivitäten reichten dabei von Ratschlägen für das Verhalten der deutschen Beobachterdelegation bei der Genfer Konferenz von 1959 (,klaren Kurs halten!“... S. 27) bis zum Einsatz als Sonderbotschafter Adenauers in Sachen Oder-NeißeGrenze (S. 50). Nach seinem Rückzug in den Himalaya als Wanderprediger und einer 1971 von dort in Sanskrit an die Deutsche Welle übermittelten Abschiedsbotschaft (S. 139) schien es allerdings still um ihn zu werden. 
Da sorgte eine zweite Generation von Dräcker-Förderern, zu der die Herausgeber gehören, für eine zumindest in diesem Umfang unerwartete Renaissance: Dräcker wurde wieder weltweit aktiv. Er durchquerte Afrika von West nach Ost (S. 59), trat bei den Vereinten Nationen in New York auf (S. 37), vergaß aber auch nicht, bei der Oberfinanzdirektion Köln ein Bundesdarlehen für den Bau einer Familiengruft zu beantragen (S. 193 ff.). Vor allem aber gelang ihm, nachdem 1976 Meldungen über sowjetische Truppenbewegungen im „bulgarisch-albanischen Grenzgebiet“ kolportiert wurden, der einwandfreie Nachweis, dass Bulgarien und Albanien gar keine gemeinsame Grenze haben (S. 39 ff.). Auch sollte nicht vergessen werden, dass der damalige Außenminister Genscher 1979 den Orden wider den Tierischen Ernst nur bekam, weil der eigentlich vorgesehene Dräcker zum Verleihungstermin nicht erscheinen konnte (S. 91 ff.). Noch weniger bekannt war bisher, dass im Vorlesungsverzeichnis der Ruhruniversität Bochum 1980/81 Dräcker mit einem Seminar über Indische Mythologie vertreten war und der damalige Rektor Knut Ipsen mit dem AA hierüber korrespondierte (S. 117 ff.) ...

Auch unter der zahlreichen Nachkommenschaft Dräckers scheint sein Erbgut aktiv zu sein: Am 01.04.1994 schlug sein Sohn Edward F. Dräcker-Mountgodes die Förderung eines Musikfestivals auf zwei Inseln im verdunstenden Aralsee vor (S. 212 ff.). Schon 1985 hatte seine Enkelin Edeltraud F. Dräcker in Beirut einen lichtvollen Vortrag über „In Oriente Lux?" gehalten, der durch bürgerkriegsbedingten Lichtausfall behindert wurde (S. 207 f., 223 ff.) ... Vor allem aber wird das auch manche Dräcker-Anhänger überraschende Auftreten seiner Tochter Anna Dräcker in dem Dokumentarfilm „Das Phantom von Bonn“ von 1996, die es in der DDR mit Hilfe des Zuchtbullen „Friedemann“ zur Heldin der sozialistischen Arbeit gebracht hatte, überzeugend aufgeklärt und dokumentiert (S. 201 ff.).

Hier ist freilich Vorsicht in der Wortwahl angesagt: Kein geringerer als Ernst Jünger hat 1997 Dräcker den Charakter eines Phantoms aberkannt (S. 241). Er hält ihn für die Personifikation von unausgelebten Aspekten seiner Schöpfer.

Dem Nomos-Verlag gebührt Dank dafür, dass er neben anderen prominenten fiktiven Zeitgenossen wie dem Abgeordneten Jakob Mierscheid und dem Verfassungsrechtler F.G. Nagelmann (vgl. S. 174 ff.) nun auch Dräcker eine der Öffentlichkeit zugängliche geistige Heimstatt bietet. Dem AA aber mögen Dräcker und seine Nachkommen noch lange erhalten bleiben; denn wie der mit der Sprachausbildung deutscher Nachkriegsdiplomaten eng verbundene Anglist R.H. Haferkorn schon 1967 erkannte (S. 6): „As long as Dracker's going strong, there's hope that nothing will go wrong."

Karl Leuteritz, Königswinter 